\title{
Asset Bubbles and Monetary Policy
}

\author{
Feng Dong* Jianjun Miao $\quad$ Pengfei Wang ${ }^{\ddagger}$
}

This Version: January 2017

First Version: December 2016

\begin{abstract}
We provide an infinite-horizon model of rational asset bubbles in a Dynamic New Keynesian framework. Entrepreneurs are heterogeneous in investment efficiency and face credit constraints. They can trade land as an asset, which also serves as collateral to borrow from banks with reserve requirements. Land commands a liquidity premium and a land bubble can emerge. Monetary policy can affect the condition for the existence of a bubble, its steady-state size, and its dynamics including the initial size. The 'leaning against the wind' interest rate policy will reduce the bubble volatility, but it may come at the cost of raising the inflation volatility. Whether monetary policy should respond to asset bubbles depends on the particular interest rate rule adopted by the central bank and on the exogenous shocks hitting the economy.
\end{abstract}

JEL Classification: E13, E32, E44, E52, G12

Keywords: asset bubble, monetary policy, Dynamic New Keynesian model, credit constraints, multiple equilibria, sentiment

\footnotetext{
*Antai College of Economics and Management, Shanghai Jiao Tong University, Shanghai, China. Tel: (+86) 21-52301590. Email: fengdong@sjtu.edu.cn

${ }^{\dagger}$ Department of Economics, Boston University, 270 Bay State Road, Boston, MA 02215. Tel.: 617-353-6675. Email: miaoj@bu.edu. Homepage: http://people.bu.edu/miaoj.

${ }^{\ddagger}$ Department of Economics, Hong Kong University of Science and Technology, Clear Water Bay, Hong Kong. Tel: (+852) 2358 7612. Email: pfwang@ust.hk
} 
"We need to explicitly integrate bubbles, a combination of rational and nonrational intuitive human responses, and other aspects of behavioral economics into our monetary policy models." Greenspan (2015)

\section{Introduction}

The booms and busts of asset prices in the stock markets and real estate markets around the world have typically been associated with business cycles in the macroeconomy (Borio, Kennedy, and Prowse (1994) and Jordà, Schularick, and Taylor (2015)). The general public, policy makers, and academic researchers often attribute the large movements of asset prices to the rise and fall of bubbles because asset price volatility cannot be explained entirely by fundamentals (Shiller (1981)). How do asset bubbles affect the real economy? How does monetary policy affect asset bubbles? Should monetary policy respond to asset bubbles? The goal of our paper is to provide a theoretical framework to address these questions.

These questions have been the subject of a heated debate in the literature. Two views are prevalent as summarized by Galí (2014). ${ }^{1}$ First, central banks should view price stability and financial stability as highly complementary and mutually consistent objectives. Even if asset prices can amplify and propagate shocks, the gain to including asset prices in monetary policy rules may be slight (Bernanke and Gertler (1999, 2001)). Moreover, non-fundamental shocks driven asset bubbles are highly unpredictable. Thus monetary policy should not respond to asset prices. Second, central banks should act preemptively in constraining asset price booms, by raising interest rates or decreasing money supply sufficiently to prevent the formation of a bubble. ${ }^{2}$ Such a policy, often referred to as "leaning against the wind," may call for a change in the inflation target.

One reason for the debate is due to the fact that there is no consensus theoretical framework for understanding the formation of asset bubbles and the mechanism of how asset bubbles interact with the macroeconomy and monetary policy. The starting point of the debate is the model of Bernanke and Gertler (1999) who introduce an irrational bubble to the model of Bernanke, Gertler, and Gilchrist (1999) (henceforth BGG). The former model cannot address the question of how and why a bubble can emerge and burst under rational expectations. We contribute to the literature by providing an infinite-horizon model of rational asset bubbles in a Dynamic New Keynesian (DNK) framework. The key ingredient of our model is that entrepreneurs (or firms) are heterogenous and face credit constraints. In a frictionless Arrow-Debreu economy, rational bubbles cannot emerge and movements of asset prices reflect changes in underlying economic fundamentals. In this case central banks should have no concern about asset prices. By contrast, due to credit constraints,

\footnotetext{
${ }^{1}$ See Gilchrist and Leahy (2002) for a survey of this literature. See Schularick and Taylor (2012) and Brunnermeier and Schnabel (2015) for empirical evidence.

${ }^{2}$ See, e.g., Borio and Lowe (2002), Cecchetti et al. (2000), Issing (2009), ECB (2010), and Blanchard et al. (2012).
} 
an intrinsically useless asset (e.g., land) can provide liquidity and command a liquidity premium. ${ }^{3}$ If all agents believe land is valuable, this belief can be self-fulfilling. Land as an asset can raise entrepreneurs' net worth and can also serve as collateral for loans. Efficient entrepreneurs sell land to inefficient ones to finance investment and hence land can be traded at a positive price. A land bubble has a positive intensive margin effect in that it raises an entrepreneur's net worth and hence his investment. It also has an extensive margin effect in that inefficient entrepreneurs must hold the bubble and will not make investment. The net effect on aggregate investment is typically positive.

To introduce money and monetary policy, we incorporate a banking system with legal restrictions in that banks must meet reserve requirements. Reserve requirements generate a spread between the lending rate and the deposit rate. Households and entrepreneurs can save by making deposits in banks and banks can lend to investing entrepreneurs. The central bank changes money supply by changing reserves (high powered money or monetary base). Monetary policy is conducted by following an interest rate rule. In this case money supply is endogenous. To allow monetary policy to have a large impact on the real economy, we introduce monopolistic competition and sticky prices as in Calvo (1983).

Our main results can be summarized as follows. First, monetary policy can affect the condition for the existence of a bubble. High inflation erodes entrepreneurs' real balance and hence their net worth, generating a large liquidity premium for holding a bubble asset. When the liquidity premium is sufficiently high, a bubble can emerge. Thus a permanent rise of the inflation target by raising money supply can fuel a bubble. The higher the inflation target, the more likely a bubble can emerge. On the other hand, if the economy has a bubble initially, a permanent cut of the inflation target by lowing money supply can prick a bubble.

Second, monetary policy can affect the steady-state size and the dynamics of an asset bubble including its initial size. In particular, a higher inflation target is associated with a higher steady-state size of the bubble. An expansionary monetary policy by cutting the interest rate or raising money supply can raise the initial size of the asset bubble, which in turn generates a large amplification effect of monetary policy. Moreover, the coefficients in the interest rate rule affect the dynamics of the asset bubble in response to exogenous shocks. A higher interest rate response to asset bubbles reduces the bubble volatility, but may raise the inflation volatility.

Third, whether monetary policy should respond to asset bubbles depends on the particular interest rate rule adopted by the central bank and on the exogenous shocks hitting the economy. We consider two types of interest rate rules: (i) a Taylor rule, which responds to inflation and the output gap between the actual level of output and its steady-state level, and (ii) an inflation targeting rule, which responds to expected inflation, but not output gap. We consider two types of

\footnotetext{
${ }^{3}$ Introducing rents for land will complicate our analysis without changing our key insights. See Miao and Wang (2015a,b), Miao, Wang, and Zha (2014), and Miao, Wang, and Xu (2015) for models of rational bubbles attached to assets with dividends or rents.
} 
shocks: (i) a fundamental TFP shock, and (ii) a non-fundamental sentiment shock to the bubble. We include a weight on the asset bubble in the interest rate rules and search for an optimal weight to maximize household utility. Our calibrated model shows that, conditional on a TFP shock, the central bank under the Taylor rule should cut the nominal interest rate by about $1.08 \%$ per annum when the asset bubble rises by $1 \%$ from the steady state. The welfare gain is a $0.34 \%$ permanent increase in consumption. Conditional on the sentiment shock, the central bank under the Taylor rule should cut the nominal interest rate by about $1.44 \%$ per annum when the asset bubble rises by $1 \%$ from the steady state. In response to a positive TFP shock, an efficient real business cycles model implies positive comovements of consumption, investment, output, and labor. But labor falls under the Taylor rule in a DNK model (Galí (1999)). Cutting interest rates when the asset bubble rises can raise aggregate demand and hence labor. In response to a positive sentiment shock, asset bubbles rise, but consumption falls on impact under the simple Taylor rule because the nominal and real interest rates rise too much. Cutting interest rates when asset bubbles rise can allow consumption to rise, benefitting households.

By contrast, under the inflation targeting rule, the optimal coefficients on the asset bubble are generally a very small negative number. The welfare gains are also quite small, especially for the strong inflation targeting rule considered by Bernanke and Gertler (1999) and Gilchrist and Leahy (2002). As argued by Bernanke and Gertler (1999), to the extent that asset bubbles tend to be positively correlated with movements in output and inflation, policies based on these variables subsume most of the gains from reacting to asset bubbles. In fact, in response to a TFP shock or a sentiment shock, the simple strong inflation targeting rule can generate the right comovements of macroeconomic quantities, giving very small welfare gains from reacting to asset bubbles.

\section{Basic Intuition and Related Literature}

Our model features a standard aggregate supply block as in the DNK literature. The key part of our model is about aggregate demand and the key building block is about asset pricing equations. Without aggregate uncertainty, our model implies that deposits (or bond) and land satisfy the following two asset pricing equations

$$
\begin{aligned}
1 & =S D F_{t+1} \frac{R_{t}}{\Pi_{t+1}}\left(1+L I Q_{t+1}\right), \\
p_{t}^{h} & =S D F_{t+1} p_{t+1}^{h}\left(1+L I Q_{t+1}^{h}\right),
\end{aligned}
$$

where $S D F_{t+1}, R_{t}$, and $\Pi_{t+1}$ denote the stochastic discount factor (SDF), the nominal interest rate, and the inflation rate between periods $t$ and $t+1$, respectively, $p_{t}^{h}$ denotes the land price, and $L I Q_{t+1}$ and $L I Q_{t+1}^{h}$ are the liquidity premiums for the deposits and land, respectively. ${ }^{4}$ The

\footnotetext{
${ }^{4}$ Equations (1) and (2) follow from (24) and (42) with $\delta_{h}=0$.
} 
liquidity premium comes from credit constraints.

Land is intrinsically useless in that it does not pay any dividend. Its fundamental value is zero as the equilibrium with $p_{t}^{h}=0$ for all $t$ satisfies (2). There may exist a bubbly equilibrium in which $p_{t}^{h}>0$ for all $t$. In a steady state with an infinitely lived representative agent, the SDF is equal to his subjective discount factor $\beta \in(0,1)$. For a bubble $p_{t}^{h}=p_{t+1}^{h}>0$ to exist in the steady state, equation (2) becomes

$$
1=\beta\left(1+L I Q^{h}\right)
$$

This equation cannot hold in a frictionless model without liquidity premium $L I Q^{h}=0$, but can hold if there is a positive liquidity premium $L I Q^{h}>0 .{ }^{5}$ The liquidity premium provides a benefit for holding a bubble, even though the bubble asset does not provide any dividends, so that discounting by $\beta$ cannot eliminate its value in the steady state. We have elaborated this point in our previous studies (e.g., Miao and Wang (2012, 2014, 2015a,b), Miao, Wang, and Xu (2015), Miao, Wang, and $\mathrm{Xu}$ (2016), and Miao, Wang, and Zhou (2015, 2016)). Our analysis of the condition for the existence of a bubble revolves around the existence of a solution to the preceding equation and how monetary policy affects $L I Q^{h}$.

In the special case of $L I Q_{t+1}=L I Q_{t+1}^{h}$, equations (1) and (2) imply that the growth rate of the bubble is equal to the real interest rate

$$
p_{t}^{h}=\frac{p_{t+1}^{h}}{R_{t} / \Pi_{t+1}} .
$$

This equation also holds in overlapping generations (OLG) models in which a bubble can exist without liquidity premium because the SDF is not equal to $\beta$ in the steady state of OLG models. In particular, equations (1) and (3) imply that $S D F=R / \Pi=1$ in the steady state. The existence condition is then about whether there is a solution to this equation.

Our model is consistent with the conventional wisdom that monetary policy can have an impact on asset price bubbles and that monetary policy can fuel or prick a bubble. Galí (2014) challenges this wisdom based on an OLG model. The OLG framework naturally incorporates household heterogeneity and incomplete market participation, which can allow a bubble to emerge without any other frictions (Samuelson (1958) and Tirole (1985)). Our infinite-horizon model features financial frictions and has the advantage of integrating into the dynamic stochastic general equilibrium framework or the DNK framework and hence has the potential to be quantified (see Ikeda (2013) and Miao, Wang, Xu (2015)). After all, asset bubbles are a quantitative observation and theory of bubbles would be vacuous if it cannot be quantified.

Galí (2014) sets up an elegant simple model in which equilibrium dynamics can be summarized by a unidimensional system based on (3). He shows that the bubble existence condition is

\footnotetext{
${ }^{5}$ More technically, the transversality condition will rule out bubbles without liquidity premium. This condition is not needed in OLG models with finitely lived agents.
} 
independent of monetary policy. He also shows that his unidimensional equilibrium system has a continuum of stable bubbly steady states and a continuum of unstable bubbly steady states. He focuses on a stable bubbly steady state and assumes that the bubble $p_{t}^{h}$ is a backward-looking predetermined variable. In this case the initial size of the bubble $p_{0}^{h}$ is exogenously given and independent of monetary policy. Equation (3) then implies that a larger real interest rate generates a higher growth rate of the bubble. By contrast, the asset bubble in our model is a nonpredetermined forward-looking variable like any asset prices. Our equilibrium system is multi-dimensional and also features a continuum of bubbly steady states. But any bubbly steady state is a local saddle point. ${ }^{6}$ In response to an exogenous shock, the initial size of the asset bubble jumps and provides a powerful amplification mechanism. In our model monetary policy affects the initial size of the bubble and its dynamics through interest rates and liquidity premium.

Like Galí (2014), we find that the leaning against the wind policy may not be optimal, but for a different reason. Our model shows that this policy can lower the bubble volatility at the expense of raising the inflation volatility. Galí's model shows that this policy may raise the bubble volatility and reduce the dividend volatility depending on the size of the bubble. Inflation does not cause a welfare loss in his model.

Caballero and Krishnamurthy (2006), Farhi and Tirole (2012), Martin and Ventura (2012, 2015), and Asriyan et al. (2016) introduce credit constraints to OLG models of asset bubbles. Only Asriyan et al. (2016) introduce money and monetary policy. All these papers do not derive asset pricing equations like (1) and (2) and do not discuss the critical role of the liquidity premium in creating a bubble. The role of liquidity premium is emphasized by Kiyotaki and Moore (2008) in their infinite-horizon model with credit constraints. They focus on fiat money, which is also a pure bubble. Our model borrows some insights from theirs and differs from theirs in many ways: (i) the bubble asset in our model also serves as collateral, (ii) we have a DNK framework with sticky prices, and (iii) we have a banking system with reserve requirements. The reserve requirements in our model are critical for the non-superneutrality of money and for monetary policy to affect the condition for the existence of a bubble.

Our paper is also related to infinite-horizon real models of rational bubbles with credit constraints (Santos and Woodford (1997), Kocherlakota (2009), Wang and Wen (2012), Miao and Wang (2012, 2014, 2015a, 2015b), Hirano and Yanagawa (2013), Miao, Wang, and Zha (2014), Miao, Wang, and Xu (2015), Miao, Wang, and Xu (2016), Miao, Wang and Zhou (2015, 2016), and Aoki and Nikolov (2015)). ${ }^{7}$ Ikeda (2013) introduces monetary policy and wage rigidities to the model of Miao, Wang and Xu (2015). Based on Bayesian estimations, he shows that the optimal

\footnotetext{
${ }^{6}$ This is a numerical result because our equilibrium system is too complicated to permit a theoretical result. We have obtained this result numerically in Miao, Wang, and $\mathrm{Xu}$ (2015) and formally proved this result theoretically in simpler models of Miao and Wang (2012, 2015a, 2015b) and Miao, Wang and Zhou (2015).

${ }^{7}$ See Miao (2014) for a recent survey.
} 
monetary policy calls for monetary tightening to restrain the boom at the cost of greater inflation volatility.

More broadly, our model is related to the large literature on the relationship between monetary policy and asset prices (see Gilchrist and Leahy (2002) for a survey). Our model shares many insights with Kiyotaki and Moore (1997), BGG (1999), and Bernanke and Gertler (1999, 2001), in which the financial accelerator, bank lending, net worth, and balance sheet channels are important transmission and propagation mechanisms. Our result that a strong inflation targeting rule does not call for the need to respond to asset bubbles because the welfare gain is too small confirms the early finding of Bernanke and Gertler (1999), albeit asset bubbles are rational in our model.

\section{The Model}

Consider an infinite-horizon economy consisting of households, firms, retailers, financial intermediaries (banks), and a government (monetary authority). Following BGG (1999), we assume that retailers are monopolistically competitive and their role is to introduce nominal price rigidities.

\subsection{Households}

There is a continuum of identical households of measure unity. The representative household is an extended family consisting of workers, entrepreneurs, and bankers. Each entrepreneur runs a firm and workers supply labor to firms. Bankers are identical and each banker manages a bank. The family and firms can save by making deposits in banks which in turn make loans to borrowers. Entrepreneurs, bankers, and retailers hand in their dividends to the household who is the shareholder. Each household chooses consumption $\left\{C_{t}\right\}$, labor supply $\left\{N_{t}\right\}$, and deposits $\left\{S_{a, t+1}\right\}$ to maximize utility

$$
\max _{\left\{C_{t}, S_{a, t+1}, N_{t}\right\}} E_{0} \sum_{t=0}^{\infty} \beta^{t}\left(\ln C_{t}-\psi N_{t}\right),
$$

subject to

$$
C_{t}+\frac{S_{a, t+1}}{P_{t}}=w_{t} N_{t}+D_{t}+\frac{R_{t-1} S_{a t}}{P_{t}}+X_{t},
$$

where $\beta$ is the subjective discount factor, $w_{t}$ is the real wage, $P_{t}$ is the price level, $D_{t}$ is the total dividends from bankers, entrepreneurs, and retailers, $R_{t-1}$ is the nominal interest rate (deposit rate) between periods $t-1$ and $t$, and $X_{t}$ denotes the sum of money transfers and lump-sum taxes/transfers from the government. Suppose that the household cannot borrow so that $S_{a, t+1} \geq 0$.

The first-order conditions imply that

$$
\begin{aligned}
w_{t} & =\frac{\psi}{\Lambda_{t}} \\
1 & \geq E_{t}\left[\frac{\beta \Lambda_{t+1}}{\Lambda_{t}} \frac{R_{t}}{\Pi_{t+1}}\right], \text { with equality when } S_{a t+1}>0
\end{aligned}
$$


where $\Lambda_{t}=1 / C_{t}$ denotes the household marginal utility and $\Pi_{t+1}=P_{t+1} / P_{t}$ denotes the (gross) inflation rate between periods $t$ and $t+1$.

\subsection{Banks}

Bankers are identical of measure unity. At each time $t$, the representative bank receives total deposits $S_{t+1}$ and chooses loans $L_{t+1}$ and reserves $M_{t+1}$. For simplicity, suppose that there is no bank net worth and that there is no interest on reserves. Reserves are often called high-powered money or monetary base. We do not consider currency in circulation or inter-bank loan markets in this model.

The balance sheet equation is given by

$$
L_{t+1}+M_{t+1}=S_{t+1}
$$

The bank is also subject to the reserve requirement

$$
M_{t+1} \geq \lambda S_{t+1}
$$

where $\lambda \in(0,1)$ denotes the required reserve ratio. The bank's objective is to maximize profits

$$
\max _{M_{t+1}, L_{t+1}} E_{t} \frac{\beta \Lambda_{t+1}}{\Lambda_{t}}\left(\frac{L_{t+1} R_{l t}+M_{t+1}-S_{t+1} R_{t}}{P_{t+1}}\right)
$$

subject to (8) and (9), where $R_{l t}$ denotes the loan rate between periods $t$ and $t+1$.

We can show that, as long as $R_{l t}>R_{t}$, the constraint (9) binds so that

$$
M_{t+1}=\lambda S_{t+1}
$$

and

$$
R_{l t}=\frac{R_{t}-\lambda}{1-\lambda}
$$

This equation implies that the equilibrium deposit rate must satisfy $R_{t}>1$ for $R_{l t}>R_{t}$ to hold. It also shows that the bank makes zero profit and the lending rate $R_{l t}$ increases with the deposit rate for the bank to break even because reserves do not bear any interest.

\subsection{Firms}

Each entrepreneur $j \in[0,1]$ runs a firm that combines labor $N_{j t}$ and capital $K_{j t}$ to produce an intermediate (wholesale) good $j$ according to the technology

$$
Y_{j t}=A_{t} K_{j t}^{\alpha} N_{j t}^{1-\alpha}, \alpha \in(0,1),
$$

where $A_{t}$ denotes total factor productivity (TFP), which follows an $\mathrm{AR}(1)$ process

$$
\ln A_{t}=\rho_{a} \ln A_{t-1}+\varepsilon_{a t},
$$


where $\left\{\varepsilon_{a t}\right\}$ is a white noise process. The entrepreneur sells wholesale goods to retailers at the real price $p_{w t}$. The static profit maximization problem yields

$$
R_{k t} K_{j t}=\max _{N_{j t}} p_{w t} A_{t} K_{j t}^{\alpha} N_{j t}^{1-\alpha}-w_{t} N_{j t}
$$

where

$$
R_{k t}=\alpha\left(\frac{1-\alpha}{w_{t}}\right)^{\frac{1-\alpha}{\alpha}}\left(p_{w t} A_{t}\right)^{\frac{1}{\alpha}} .
$$

and the first-order condition gives labor demand

$$
w_{t}=(1-\alpha) p_{w t} A_{t} K_{j t}^{\alpha} N_{j t}^{-\alpha}
$$

At the beginning of period $t$, the entrepreneur faces idiosyncratic investment-specific shock $\varepsilon_{j t}$ and makes investment $I_{j t}$ to increase his capital stock so that the law of motion for capital follows

$$
K_{j t+1}=(1-\delta) K_{j t}+\varepsilon_{j t} I_{j t}
$$

where $\delta \in(0,1)$ represents the depreciation rate. Suppose that the cumulative distribution function of $\varepsilon_{j t}$ is $F$ and the density function is $f$ on $\left[\varepsilon_{\min }, \varepsilon_{\max }\right] \subset[0, \infty)$ and $\varepsilon_{j t}$ is independently and identically distributed across firms and over time. Assume that there is no insurance market against the idiosyncratic investment-specific shock and that investment is irreversible at the firm level so that $I_{j t} \geq 0$.

The entrepreneur chooses to save $S_{j t+1} \geq 0$ in banks at the deposit rate $R_{t}$ and borrow $L_{j t+1} \geq 0$ at the lending rate $R_{l t}$. He is endowed with $\delta_{h} \in(0,1)$ units of an intrinsically useless bubble asset (say, land or commercial real estate) at the beginning of each period $t$. Its nominal price is denoted by $P_{t \mid t}^{h}$, which is nonnegative by free disposal. Each period a fraction $\delta_{h}$ of each vintage of the bubble assets is assumed to lose its value, due to depreciation for example. This implies that the total amount of bubble assets outstanding remains constant and is normalized to one. Our modeling of such recurrent bubbles is related to Martin and Ventura (2012), Galí (2014), and Miao, Wang, and $\mathrm{Xu}$ (2015). The purpose is to introduce a non-fundamental sentiment shock that drives the movements of the asset bubble.

Entrepreneurs can trade each vintage of land, but land trading is illiquid. Following Kiyotaki and Moore (2008), we impose the resaleability constraint

$$
H_{j, t+1 \mid t-k} \geq \omega\left(1-\delta_{h}\right) H_{j, t \mid t-k} \geq 0, \quad k=0,1,2, \ldots
$$

where $\omega \in(0,1), H_{j, t+1 \mid t-k}$ represents period $t$ choice of land endowed in period $t-k$, and $H_{j, t \mid t-k}$ represents period $t-1$ choice of land endowed in period $t-k$. By convention, we set $H_{j, t \mid t}=$ $\delta_{h} /\left(1-\delta_{h}\right)$. Constraint (16) says that the entrepreneur can sell at most a fraction $(1-\omega)$ of his undepreciated land each period due to market illiquidity. In addition, he cannot short sell land. 
A key assumption is that entrepreneurs face borrowing constraints due to imperfect contract enforcement. We impose

$$
0 \leq L_{j t+1} \leq \theta \omega\left[\left(1-\delta_{h}\right) \sum_{k=0}^{\infty} P_{t \mid t-k}^{h} H_{j, t \mid t-k}\right]+\mu P_{t} K_{j t}
$$

where $\theta \in(0,1), \mu \in(0,1)$, and $P_{t \mid t-k}^{h}$ denotes the period $t$ nominal price of land at vintage $t-k$. The interpretation of the constraint above is that the entrepreneur's borrowing is limited by the collateral value of a fraction $\theta \in(0,1)$ of his nontraded existing undepreciated land plus newly endowed land and a fraction $\mu$ of his existing capital. ${ }^{8}$

We can write the flow-of-funds constraints as

$$
\begin{gathered}
D_{j t}+I_{j t}+\sum_{k=0}^{\infty} p_{t \mid t-k}^{h} H_{j, t+1 \mid t-k}+\frac{1}{P_{t}}\left(S_{j t+1}+L_{j t} R_{l t-1}\right) \\
=R_{k t} K_{j t}+\frac{1}{P_{t}}\left(S_{j t} R_{t-1}+L_{j t+1}\right)+\left(1-\delta_{h}\right) \sum_{k=0}^{\infty} p_{t \mid t-k}^{h} H_{j, t \mid t-k},
\end{gathered}
$$

where $D_{j t}$ denotes real dividends and $p_{t \mid t-k}^{h}=P_{t \mid t-k}^{h} / P_{t}$ denotes the real land price. Suppose that equity finance is so costly that the firm does not issue new equity. ${ }^{9}$ Thus we impose

$$
D_{j t} \geq 0
$$

The entrepreneur's objective is to maximize the discounted present value of dividends. We can write his decision problem by dynamic programming

$$
\begin{aligned}
& V_{t}\left(K_{j t}, S_{j t}, L_{j t},\left\{H_{j, t \mid t-k}\right\}_{k=0}^{\infty}, \varepsilon_{j t}\right) \\
= & \max _{\left\{I_{j t}, S_{j t+1}, L_{j t+1}, H_{j t+1}\right\}} D_{j t}+\beta E_{t} \frac{\Lambda_{t+1}}{\Lambda_{t}} V_{t+1}\left(K_{j t+1}, S_{j t+1}, L_{j t+1},\left\{H_{j, t+1 \mid t-k}\right\}_{k=0}^{\infty}, \varepsilon_{j t+1}\right),
\end{aligned}
$$

subject to (15), (16), (17), (18), and (19), where we have used the household's intertemporal marginal rate of substitution as the stochastic discount factor. Here $V_{t}(\cdot)$ denotes the value function.

Define Tobin's (marginal) Q as

$$
q_{t}^{k} \equiv \frac{\partial}{\partial K_{j t+1}} E_{t} \frac{\beta \Lambda_{t+1}}{\Lambda_{t}} V_{t+1}\left(K_{j t+1}, S_{j t+1}, L_{j t+1},\left\{H_{j, t \mid t-k}\right\}_{k=0}^{\infty}, \varepsilon_{j t+1}\right)
$$

The following proposition characterizes the entrepreneur's optimal decisions.

\footnotetext{
${ }^{8}$ Unlike Kiyotaki and Moore (1997), we do not use future values of land and capital as collateral. Using future values as collateral will complicate algebra significantly without changing our key insights. See Caballero and Krishnamurthy (2006), Miao and Wang (2015b), and Miao, Wang and Zhou (2015) for related discussions.

${ }^{9}$ Our key insights will not change as long as new equity issues are sufficiently limited (see Miao and Wang (2005b) and Miao, Wang, and $\mathrm{Xu}(2015))$.
} 
Proposition 1 In an equilibrium with $R_{l t}>R_{t}>1$, there exist two cut-off values $\varepsilon_{t}^{*}$ and $\varepsilon_{t}^{* *}$ such that the decision rules are give by $I_{j t}=0$ if $\varepsilon_{j t}<\varepsilon_{t}^{*}$ and

$$
\begin{aligned}
& I_{j t}=R_{k t} K_{j t}+\frac{1}{P_{t}}\left(S_{j t} R_{t-1}-S_{j t+1}+L_{j t+1}-L_{j t} R_{l t-1}\right) \\
& +(1-\omega)\left(1-\delta_{h}\right) \sum_{k=0}^{\infty} p_{t \mid t-k}^{h} H_{j, t \mid t-k} \text { if } \varepsilon_{j t} \geq \varepsilon_{t}^{*} \\
& S_{j t+1}= \begin{cases}0, & \text { if } \varepsilon_{j t} \geq \varepsilon_{t}^{*} \\
\text { indeterminate, } & \text { otherwise }\end{cases} \\
& \frac{L_{j t+1}}{P_{t}}= \begin{cases}0, & \text { if } \varepsilon_{j t}<\varepsilon_{t}^{* *} \\
\theta \omega\left(1-\delta_{h}\right) \sum_{k=0}^{\infty} p_{t \mid t-k}^{h} H_{j, t \mid t-k}+\mu K_{j t}, & \text { otherwise }\end{cases} \\
& H_{j, t+1 \mid t-k}=\left\{\begin{array}{ll}
\omega\left(1-\delta_{h}\right) H_{j, t \mid t-k}, & \text { if } \varepsilon_{j t} \geq \varepsilon_{t}^{*} \\
\text { indeterminate, } & \text { otherwise }
\end{array},\right.
\end{aligned}
$$

where the cut-off values satisfy

$$
\begin{gathered}
\varepsilon_{t}^{*}=\frac{1}{q_{t}^{k}}, \\
\varepsilon_{t}^{* *}=\frac{R_{l t}}{R_{t}} \varepsilon_{t}^{*},
\end{gathered}
$$

and $q_{t}^{k}, R_{t}$, and $p_{t \mid t-k}^{h}$ satisfy ${ }^{10}$

$$
\begin{aligned}
q_{t}^{k}= & \beta E_{t} \frac{\Lambda_{t+1}}{\Lambda_{t}} R_{k t+1}\left[1+\int_{\varepsilon_{t+1}^{*}}^{\varepsilon_{\max }}\left(q_{t+1}^{k} \varepsilon-1\right) d F(\varepsilon)\right] \\
+ & \beta E_{t} \frac{\Lambda_{t+1}}{\Lambda_{t}} q_{t+1}^{k}(1-\delta)+\beta E_{t} \frac{\Lambda_{t+1}}{\Lambda_{t}} \mu \int_{\varepsilon_{t+1}^{* *}}^{\varepsilon_{\max }}\left(q_{t+1}^{k} \varepsilon-\frac{R_{l t}}{R_{t}}\right) d F(\varepsilon), \\
& 1=\beta E_{t} \frac{\Lambda_{t+1}}{\Lambda_{t}} \frac{R_{t}}{\Pi_{t+1}}\left[1+\int_{\varepsilon_{t+1}^{*}}^{\varepsilon_{\max }}\left(q_{t+1}^{k} \varepsilon-1\right) d F(\varepsilon)\right] \\
p_{t \mid t-k}^{h}= & \left(1-\delta_{h}\right) \beta E_{t} \frac{\Lambda_{t+1}}{\Lambda_{t}} p_{t+1 \mid t-k}^{h}\left[1+(1-\omega) \int_{\varepsilon_{t+1}^{*}}^{\varepsilon_{\max }}\left(q_{t+1}^{k} \varepsilon-1\right) d F(\varepsilon)\right] \\
& +\left(1-\delta_{h}\right) \beta \theta \omega E_{t} \frac{\Lambda_{t+1}}{\Lambda_{t}} p_{t+1 \mid t-k}^{h} \int_{\varepsilon_{t+1}^{* *}}^{\varepsilon_{\max }}\left(q_{t+1}^{k} \varepsilon-\frac{R_{l t}}{R_{t}}\right) d F(\varepsilon) .
\end{aligned}
$$

This proposition shows that there are two cutoff values $\varepsilon_{t}^{*}$ and $\varepsilon_{t}^{* *}$ such that the firm makes investment if and only if $\varepsilon_{j t}>\varepsilon_{t}^{*}=1 / q_{t}^{k}$. This is consistent with Tobin's rule. Making one unit of investment costs one unit of consumption goods, but the investment transforms into $\varepsilon_{j t}$ units of capital and hence the marginal benefit is $q_{t}^{k} \varepsilon_{j t}$. When the marginal benefit is higher than the

\footnotetext{
${ }^{10}$ The usual transversality conditions must also hold. Moreover, for ease of exposition, we assume that parameter values are such that $\varepsilon_{t}^{*}$ and $\varepsilon_{t}^{* *}$ are in the interior of $\left(\varepsilon_{\min }, \varepsilon_{\max }\right)$.
} 
marginal cost, the firm makes investment. When investing, it will not save and sell land as much as possible to finance investment. Since the lending rate $R_{l t}$ is higher than the deposit rate $R_{t}$, the firm will choose to borrow from banks if and only if investment is sufficiently profitable. Namely, the investment efficiency must exceed the cutoff $\varepsilon_{t}^{* *}>\varepsilon_{t}^{*}$. The ratio of these two cutoffs $\varepsilon_{t}^{* *} / \varepsilon_{t}^{*}$ is equal to the ratio of the lending rate to the deposit rate, which is interpreted as the external finance premium as in BGG (1999). When the firm chooses to borrow, the borrowing reaches the credit limit.

Equations (23), (24), and (25) are the asset pricing equations for capital, deposits, and land of vintage $t-k$. In addition to the usual terms in these equations, there are two integral terms deserving discussions. Both terms represent liquidity premium due to financial frictions. The first term represents the liquidity premium from internal funds, savings (deposits), and land. Since the entrepreneur sells a fraction $1-\omega$ of land when his investment efficiency exceeds $\varepsilon_{t+1}^{*}$, this fraction appears in (25). The second term represents the liquidity premium from collateral. One unit of (real) land value can allow the firm to borrow $\theta \omega$ units from banks. Borrowing one unit in period $t$ must be repaid at a external finance premium $R_{l t} / R_{t}$ in period $t+1$. The marginal benefit is $q_{t+1}^{k} \varepsilon$ in period $t+1$. Thus the preceding equation gives the expected profits from one unit of borrowing. The multiplicative factor $\left(1-\delta_{h}\right)$ represents the undepreciated value because a fraction $\delta_{h}$ of land loses its value. The multiplicative factor $\theta \omega$ appears in equation (25) because only $\theta \omega$ units can be borrowed using one unit of land value as collateral. Similarly, the factor $\mu$ appears in equation (23) because only $\mu$ dollars can be borrowed using one dollar of capital as collateral.

\subsection{Retailers}

Retailers are monopolistically competitive. In each period $t$ they buy intermediate goods from entrepreneurs at real price $p_{w t}$ and sell good $j$ at nominal price $P_{j t}$. Intermediate goods are transformed to final goods according to the CES aggregator

$$
Y_{t}=\left[\int_{0}^{1} Y_{j t} \frac{\sigma-1}{\sigma} d j\right]^{\frac{\sigma}{\sigma-1}}, \quad \sigma>1 .
$$

Thus the demand curve facing retailers is given by

$$
Y_{j t}=\left(\frac{P_{j t}}{P_{t}}\right)^{-\sigma} Y_{t},
$$

where the price index is given by

$$
P_{t} \equiv\left[\int_{0}^{1} P_{j t}^{1-\sigma} d i\right]^{\frac{1}{1-\sigma}} .
$$

To introduce price stickiness, we assume that each retailer is free to change its price in any period only with probability $1-\xi$, following Calvo (1983). Following Erceg, Henderson, and Levin 
(2000), we also assume that whenever the retailer is not allowed to reset its price, its price is automatically increased at the steady-state inflation rate. The retailer selling good $j$ chooses the nominal price $P_{t}^{*}$ in period $t$ to maximize the discounted present value of profits

$$
\max _{P_{t}^{*}} \sum_{k=0}^{\infty} \xi^{k} E_{t}\left[\frac{\beta^{k} \Lambda_{t+k}}{\Lambda_{t}}\left((1+\tau) \frac{\Pi^{k} P_{t}^{*}}{P_{t+k}}-p_{w, t+k}\right) Y_{j t+k}^{*}\right],
$$

subject to the demand curve

$$
Y_{j t+k}^{*}=\left(\frac{\Pi^{k} P_{t}^{*}}{P_{t+k}}\right)^{-\sigma} Y_{t+k},
$$

where $\tau$ denotes the output subsidy and $\Pi$ denotes the steady-state inflation target. We use household intertemporal marginal rate of substitution as the stochastic discount factor because retailers must hand in all profits to households who are the shareholders.

The first-order condition gives the pricing rule

$$
P_{t}^{*}=\frac{1}{1+\tau} \frac{\sigma}{\sigma-1} \frac{E_{t} \sum_{k=0}^{\infty}(\beta \xi)^{k} \Lambda_{t+k} p_{w, t+k} P_{t+k}^{\sigma} Y_{t+k}\left(\Pi^{k}\right)^{-\sigma}}{E_{t} \sum_{k=0}^{\infty}(\beta \xi)^{k} \Lambda_{t+k} P_{t+k}^{\sigma-1}\left(\Pi^{k}\right)^{1-\sigma} Y_{t+k}} .
$$

We set $1+\tau=\sigma /(\sigma-1)$ to completely remove the distortion due to monopolistic competition. Let $p_{t}^{*}=P_{t}^{*} / P_{t}$. We can then write the pricing rule in a recursive form as

$$
p_{t}^{*}=\frac{\Gamma_{t}^{a}}{\Gamma_{t}^{b}}
$$

where

$$
\begin{aligned}
\Gamma_{t}^{a} & =\Lambda_{t} p_{w t} Y_{t}+\beta \xi E_{t}\left(\frac{\Pi_{t+1}}{\Pi}\right)^{\sigma} \Gamma_{t+1}^{a}, \\
\Gamma_{t}^{b} & =\Lambda_{t} Y_{t}+\beta \xi E_{t}\left(\frac{\Pi_{t+1}}{\Pi}\right)^{\sigma-1} \Gamma_{t+1}^{b} .
\end{aligned}
$$

The aggregate price level satisfies

$$
P_{t}=\left[\xi\left(\Pi P_{t-1}\right)^{1-\sigma}+(1-\xi)\left(P_{t}^{*}\right)^{1-\sigma}\right]^{\frac{1}{1-\sigma}}
$$

or

$$
1=\left[\xi\left(\frac{\Pi}{\Pi_{t}}\right)^{1-\sigma}+(1-\xi) p_{t}^{* 1-\sigma}\right]^{\frac{1}{1-\sigma}}
$$

\subsection{Monetary Policy}

To close the model, we consider two types of interest rule rules for monetary policy. First, the central bank sets the nominal deposit rate to respond to the current inflation, output, and asset prices:

$$
\ln R_{t}=\ln R+\phi_{\pi} \ln \left(\Pi_{t} / \Pi\right)+\phi_{y} \ln \left(Y_{t} / Y\right)+\phi_{p} \ln \left(p_{t}^{h} / p^{h}\right)+v_{t}
$$


where $p_{t}^{h}$ denotes the aggregate land price defined later, $\Pi$ is the target inflation rate, and $R, Y$, and $p^{h}$ denote the steady-state levels of the nominal deposit rate, output, and land price. Assume that $\left\{v_{t}\right\}$ follows an $\mathrm{AR}(1)$ process

$$
v_{t}=\rho_{v} v_{t-1}+\varepsilon_{v t}
$$

where $\rho_{v} \in(0,1)$ and $\left\{\varepsilon_{v t}\right\}$ is a white noise process. In the DNK literature one often focuses on the zero-inflation steady state by setting $\Pi=1$. But we will study the case with $\Pi>1$ because a positive inflation is important for the emergence of a bubble.

Second, we consider the inflation targeting rule following Bernanke and Getter (1999) and Gilchrist and Leahy (2002):

$$
\ln R_{t}=\ln R+\phi_{\pi} E_{t} \ln \left(\Pi_{t+1} / \Pi\right)+\phi_{p} \ln \left(p_{t}^{h} / p^{h}\right)+v_{t} .
$$

As a baseline rule, we set $\phi_{p}=0$ in (36) and (37) and call the former the Taylor rule. In Section 6 we will search for the optimal value of $\phi_{p}$ to maximize household utility with full commitment.

The interest rate rule policy implies that money supply is endogenous. Let reserves follow the dynamics

$$
M_{t+1}=M_{t} \exp \left(g_{t}\right),
$$

where $g_{t}$ is the endogenous exponential growth rate of money. Assume that the increased money is transferred to households in a lump-sum manner. If one assumes that $g_{t}$ is exogenous, then the nominal interest rate will be endogenous. In our analysis below we will follow the tradition of the DNK framework to adopt the interest rate rule.

\subsection{Equilibrium System}

The market-clearing conditions for bank loans, deposits, and land are given by

$$
\int L_{j t} d j=L_{t}, \int S_{j t} d j+S_{a t}=S_{t}, \quad \int H_{j, t+1 \mid t-k} d j=\delta_{h}\left(1-\delta_{h}\right)^{k}, k=0,1,2 \ldots
$$

for all $t$. Equation (7) and (24) imply that $S_{a, t+1}=0$ because the deposit rate is too low. ${ }^{11}$ Assuming $S_{a 0}=0$, we have $S_{a t}=0$ for all $t \geq 0$.

Define aggregate capital, aggregate investment, and aggregate labor as $K_{t}=\int K_{j t} d j, I_{t}=$ $\int I_{j t} d j$, and $N_{t}=\int N_{j t} d j$. By the labor demand condition (14), we can show that the capital-labor ratio is independent of $j$ and hence we have

$$
w_{t}=(1-\alpha) p_{w t} A_{t} K_{t}^{\alpha} N_{t}^{-\alpha}
$$

Plugging (40) into (13), we can show that $R_{k t}$ is equal to the marginal revenue product of capital

$$
R_{k t}=\alpha p_{w t} A_{t} K_{t}^{\alpha-1} N_{t}^{1-\alpha} .
$$

\footnotetext{
${ }^{11}$ Similarly, households will not hold any land by equation (25), even though we allow them to trade land.
} 
Define an index for the pre-existing bubbles as

$$
p_{t}^{E}=\sum_{k=1}^{\infty} p_{t \mid t-k}^{h}\left(1-\delta_{h}\right)^{k} \delta_{h} .
$$

The size of the total new bubble is denoted by $p_{t}^{N}=\delta_{h} p_{t \mid t}^{h}$. Define the economy's aggregate bubble as $p_{t}^{h}=p_{t}^{E}+p_{t}^{N}$. Using these definitions, we can rewrite equation (25) as

$$
\begin{aligned}
p_{t}^{h}= & \beta E_{t} \frac{\Lambda_{t+1}}{\Lambda_{t}} p_{t+1}^{E}\left[1+(1-\omega) \int_{\varepsilon_{t+1}^{*}}^{\varepsilon_{\max }}\left(q_{t+1}^{k} \varepsilon-1\right) d F(\varepsilon)\right] \\
& +\beta \theta \omega E_{t} \frac{\Lambda_{t+1}}{\Lambda_{t}} p_{t+1}^{E} \int_{\varepsilon_{t+1}^{* *}}^{\varepsilon_{\max }}\left(q_{t+1}^{k} \varepsilon-\frac{R_{l t}}{R_{t}}\right) d F(\varepsilon) .
\end{aligned}
$$

This equation is analogous to equation (14) in Galí (2014). Note that $p_{t+1}^{E}$ appears on the right-hand side of (42) because all bubbles today become old tomorrow.

By Proposition 1, firms with $\varepsilon_{j t} \geq \varepsilon_{t}^{* *}$ take loans from banks and the loan volume reaches the borrowing limit in (17). Aggregating the borrowing limit, we obtain

$$
\frac{L_{t+1}}{P_{t}}=\left(\theta \omega p_{t}^{h}+\mu K_{t}\right)\left(1-F\left(\varepsilon_{t}^{* *}\right)\right) .
$$

Using (8) and (11), we can rewrite the preceding equation as

$$
m_{t+1}=\frac{\lambda}{1-\lambda}\left(\theta \omega p_{t}^{h}+\mu K_{t}\right)\left(1-F\left(\varepsilon_{t}^{* *}\right)\right)
$$

where we have used $m_{t+1} \equiv M_{t+1} / P_{t}$ to denote the real balance of reserves. This equation gives money demand. Equation (38) gives money supply

$$
m_{t+1}=\frac{m_{t}}{\Pi_{t}} \exp \left(g_{t}\right)
$$

By Proposition 1, (8), (11), (12), and the market-clearing conditions above, we can show that

$$
I_{t}=\left(R_{k t} K_{t}+\frac{m_{t}}{\Pi_{t}}+(1-\omega) p_{t}^{h}\right)\left(1-F\left(\varepsilon_{t}^{*}\right)\right)+\left(\theta \omega p_{t}^{h}+\mu K_{t}\right)\left(1-F\left(\varepsilon_{t}^{* *}\right)\right),
$$

and

$$
\begin{aligned}
K_{t+1}= & (1-\delta) K_{t}+\left(R_{k t} K_{t}+\frac{m_{t}}{\Pi_{t}}+(1-\omega) p_{t}^{h}\right) \int_{\varepsilon_{t}^{*}}^{\varepsilon_{\max }} \varepsilon d F(\varepsilon) \\
& +\left(\theta \omega p_{t}^{h}+\mu K_{t}\right) \int_{\varepsilon_{t}^{* *}}^{\varepsilon_{\max }} \varepsilon d F(\varepsilon)
\end{aligned}
$$

Equation (45) shows that aggregate investment is financed by internal funds $R_{k t} K_{t}$, the real balance $m_{t} / \Pi_{t}$ (or returns on net savings), land sales $(1-\omega) p_{t}^{h}$, and bank loans $\theta \omega p_{t}^{h}+\mu K_{t}$. The two equations above show that asset bubbles have an intensive and extensive margin effects on aggregate investment and capital accumulation. The two cutoffs $\varepsilon_{t}^{*}$ and $\varepsilon_{t}^{* *}$ reflect the extensive margin effect. 
The term $1-F\left(\varepsilon_{t}^{*}\right)$ represents the mass of firms that sell land to make investment and the term $1-F\left(\varepsilon_{t}^{* *}\right)$ represent the mass of firms that take loans to make investment.

Aggregating (27) yields

$$
Y_{t}=\frac{A_{t}}{\Delta_{t}} K_{t}^{\alpha} N_{t}^{1-\alpha}
$$

where

$$
\Delta_{t}=\int\left(\frac{P_{j t}}{P_{t}}\right)^{-\sigma} d j
$$

is the price dispersion, which satisfies the recursive equation

$$
\Delta_{t}=(1-\xi) p_{t}^{*-\sigma}+\xi\left(\frac{\Pi}{\Pi_{t}}\right)^{-\sigma} \Delta_{t-1}
$$

The resource constraint is given by

$$
C_{t}+I_{t}=Y_{t}
$$

In summary, we have shown that the equilibrium system in a neighborhood of steady state with $R_{t}>1$ consists of 21 equations (6), (12), (21), (22), (23), (24), (32), (33), (34), (35), (40), (41), (42), (43), (44), (45), (46), (47), (48), and (49), plus a monetary policy equation (36) or (37), for 22 variables $\left\{w_{t}, \varepsilon_{t}^{*}, \varepsilon_{t}^{* *}, q_{t}^{k}, R_{t}, R_{l t}, p_{t}^{*}, \Gamma_{t}^{a}, \Gamma_{t}^{b}, \Pi_{t}, p_{w t}, N_{t}, R_{k t}, p_{t}^{h}, p_{t}^{E}, m_{t}, g_{t}, I_{t}, K_{t}, Y_{t}, \Delta_{t}, C_{t}\right\}$, where $\Lambda_{t}=1 / C_{t}$. Here $K_{t}, m_{t}$, and $\Delta_{t}$ are endogenously predetermined variables. The usual transversality conditions must also hold.

As in Galí (2014), the sizes of pre-existing bubbles and new bubbles cannot be independently determined in equilibrium. That is, there could exist a continuum of bubbly equilibria. He then assumes that new bubbles follow an exogenous IID process, which is interpreted as a bubble shock. For ease of computations, we follow Miao, Wang, and Xu (2015) and assume that new bubbles account for a stochastic fraction of aggregate bubbles so that $p_{t}^{E}=s_{t} p_{t}^{h}$, where $s_{t} \in(0,1)$. Suppose that

$$
\ln s_{t}=\left(1-\rho_{s}\right) \ln s+\rho_{s} \ln s_{t-1}+\varepsilon_{s t},
$$

where $\rho_{s} \in(0,1), s \in(0,1)$ is the non-stochastic steady-state value of $s_{t}$, and $\left\{\varepsilon_{s t}\right\}$ is a white noise process. ${ }^{12}$ We can interpret $s_{t}$ as an exogenously given bubble shock or sentiment shock that drives the movements of aggregate bubbles.

\section{Steady-State Analysis}

This section conducts a steady state analysis. There are two types of steady state equilibria. In the bubbleless steady state, the land price is equal to zero. In a bubbly steady state, the land price is positive. We remove the time subscript for any variable to indicate its steady state value. Whenever necessary, we also use a variable with subscript $f$ or $b$ to indicate its bubbleless or bubbly

\footnotetext{
${ }^{12}$ We need the shock to be small $\varepsilon_{s t}$ so that $s_{t}$ is between 0 and 1.
} 
steady state value, respectively. In both types of steady states we have $p^{*}=p_{w}=\Delta=1$ and the inflation rate is equal to the growth rate of money, $\Pi=\exp (g)$. Due to the full price indexation assumed earlier, both the flexible price equilibrium and the sticky price equilibrium have the same steady states.

We first derive some common equations that hold in both the bubbleless and bubbly steady states. By equation (24), we can derive the nominal deposit rate as

$$
R=\frac{\Pi \beta^{-1}}{1+\int_{\varepsilon^{*}}^{\varepsilon_{\max }}\left(\frac{\varepsilon}{\varepsilon^{*}}-1\right) d F(\varepsilon)} \equiv R\left(\varepsilon^{*}\right) .
$$

It is straightforward to show that $R\left(\varepsilon^{*}\right)$ increases with $\varepsilon^{*}$ and $R / \Pi<1 / \beta$. Since the steady-state real interest rate $R / \Pi$ in both the bubbly and bubbleless steady states is too low, households will not hold land (even if they are allowed to trade land) and will not save in a neighborhood of either steady state so that $S_{a, t+1}=0$.

By (12) and (22), we have

$$
\varepsilon^{* *}=\frac{1-\lambda / R\left(\varepsilon^{*}\right)}{1-\lambda} \varepsilon^{*} \equiv \varepsilon\left(\varepsilon^{*}\right)
$$

We can easily check that $\varepsilon^{* *}$ increases with $\varepsilon^{*}$. Using (23) and (51), we can derive

$$
R_{k}=\frac{1}{\varepsilon^{*}} \frac{\frac{1}{\beta}-1+\delta-\mu \int_{\varepsilon^{* *}}^{\varepsilon_{\max }}\left(\varepsilon-\varepsilon^{* *}\right) d F(\varepsilon)}{1+\int_{\varepsilon^{*}}^{\varepsilon_{\max }}\left(\frac{\varepsilon}{\varepsilon^{*}}-1\right) d F(\varepsilon)} \equiv R_{k}\left(\varepsilon^{*}\right) .
$$

We will impose assumptions below such that $R>1$ so that $R_{l}>R$ and $\varepsilon^{* *}>\varepsilon^{*}$. The critical step of establishing the existence of steady state equilibria is to show the existence of a cutoff $\varepsilon^{*}$. Once this cutoff is obtained, other steady-state values can be easily derived.

\subsection{Bubbleless Steady State}

In a bubbleless steady state $p^{h}=0$ and hence we can ignore equation (25). To show the existence of a bubbleless steady state with $R_{f}>1$, we impose the following:

Assumption 1 Let $\beta E[\varepsilon]>\Pi \varepsilon_{\min }$ and $\Pi>\beta$.

The first inequality holds for any distribution with $\varepsilon_{\min }=0$ and the second is needed because it is implied by (50) for $R>1$ in steady state.

Lemma 1 Under assumption 1, there exists a unique $\underline{\varepsilon} \in\left(\varepsilon_{\min }, \varepsilon_{\max }\right)$ such that

$$
1+\int_{\underline{\varepsilon}}^{\varepsilon_{\max }}\left(\frac{\varepsilon}{\underline{\varepsilon}}-1\right) d F(\varepsilon)=\Pi \beta^{-1} .
$$

This lemma implies that $R(\underline{\varepsilon})=1$. Since $R\left(\varepsilon^{*}\right)$ increases with $\varepsilon^{*}$, we need to find an $\varepsilon^{*}>\underline{\varepsilon}$ so that $R=R\left(\varepsilon^{*}\right)>1$ in the steady state. 
Proposition 2 Suppose that assumption 1 holds and $\mu$ satisfies the assumptions in Appendix A. Then there exists a unique bubbleless steady state with $R_{f}=R\left(\varepsilon_{f}^{*}\right)>1$, where $\varepsilon_{f}^{*} \in\left(\underline{\varepsilon}, \varepsilon_{\max }\right)$ is the unique solution for $\varepsilon^{*}$ to the equation

$$
\delta=\left(R_{k}\left(\varepsilon^{*}\right)+\frac{\lambda \mu}{1-\lambda} \frac{1-F\left(\varepsilon\left(\varepsilon^{*}\right)\right)}{\Pi}\right) \int_{\varepsilon^{*}}^{\varepsilon_{\max }} \varepsilon d F(\varepsilon)+\mu \int_{\varepsilon\left(\varepsilon^{*}\right)}^{\varepsilon_{\max }} \varepsilon d F(\varepsilon),
$$

where $\varepsilon\left(\varepsilon^{*}\right)$ is given in (51).

Equation (53) is derived from the steady-state version of equation (46). The left side of (53) is the depreciation rate and the right side is the ratio of investment in efficiency units to the capital stock. Investment (in consumption units) is financed by internal funds $R_{k}\left(\varepsilon^{*}\right) K$ and the real balance of reserves (i.e., savings minus loan repayments) by equation (43)

$$
\frac{m}{\Pi}=\frac{\lambda \mu K}{1-\lambda} \frac{1-F\left(\varepsilon\left(\varepsilon^{*}\right)\right)}{\Pi} .
$$

In addition, firms with efficiency levels higher than $\varepsilon\left(\varepsilon^{*}\right)$ borrow from banks. Since land has no value in a bubbleless equilibrium, firms can only borrow against a fraction $\mu$ of their capital. This interprets the last term in (53).

After determining the investment threshold $\varepsilon_{f}^{*}$, we then derive the other threshold $\varepsilon_{f}^{* *}=\varepsilon\left(\varepsilon_{f}^{*}\right)$ using (51). The other equilibrium variables can also be easily determined as shown in the proof of Proposition 3 in Appendix A. From the analysis above, we can see clearly that our model implies non-superneutrality of money in the sense that the steady-state levels of the capital-labor ratio, consumption, and output all depend on the inflation rate.

Proposition 3 Suppose that the assumptions in Proposition 2 hold. Then in the bubbleless steady state $\varepsilon_{f}^{*}, K_{f} / N_{f}, w_{f}, Y_{f} / N_{f}$, and $C_{f}$ all decrease with $\Pi$.

The intuition is that the inflation rate $\Pi$ affects entrepreneurs' net worth and hence their investment behavior. In particular, it affects the investment cutoff $\varepsilon_{f}^{*}$ by (53). The impact on $\varepsilon_{f}^{*}$ in turn affects the mass of investing entrepreneurs and the liquidity premium and hence the real economy. Note that the assumption of the reserve requirement $\lambda \in(0,1)$ is crucial for the non-superneutrality of money and also for inflation to affect the bubbly steady state analyzed in the next subsection.

\subsection{Bubbly Steady State}

We now turn to the bubbly steady state. As in Galí (2014), there could exist a continuum of bubbly steady states because the sizes of pre-existing bubbles and new bubbles cannot be independently determined. Here we will take the fraction $s$ of pre-existing bubbles as given. The following proposition studies the existence issue. 
Proposition 4 Suppose that the assumptions in Proposition 2 hold so that there exists a bubbleless steady state with $R_{f}=R\left(\varepsilon_{f}^{*}\right)>1$, where $\varepsilon_{f}^{*}$ is the investment threshold. Then there exists a unique bubbly steady state with $R_{b}=R\left(\varepsilon_{b}^{*}\right)>R_{f}>1$, where the cutoff $\varepsilon_{b}^{*} \in\left(\varepsilon_{f}^{*}, \varepsilon_{\max }\right)$ is the unique solution for $\varepsilon^{*}$ to the equation

$$
\beta s\left(1+(1-\omega) \int_{\varepsilon^{*}}^{\varepsilon_{\max }}\left(\frac{\varepsilon}{\varepsilon^{*}}-1\right) d F(\varepsilon)\right)+\beta s \theta \omega \int_{\varepsilon\left(\varepsilon^{*}\right)}^{\varepsilon_{\max }}\left(\frac{\varepsilon}{\varepsilon^{*}}-\frac{\varepsilon\left(\varepsilon^{*}\right)}{\varepsilon^{*}}\right) d F(\varepsilon)=1,
$$

if and only if

$$
\beta s\left(1+(1-\omega) \int_{\varepsilon_{f}^{*}}^{\varepsilon_{\max }}\left(\frac{\varepsilon}{\varepsilon_{f}^{*}}-1\right) d F(\varepsilon)\right)+\beta s \theta \omega \int_{\varepsilon\left(\varepsilon_{f}^{*}\right)}^{\varepsilon_{\max }}\left(\frac{\varepsilon}{\varepsilon_{f}^{*}}-\frac{\varepsilon\left(\varepsilon_{f}^{*}\right)}{\varepsilon_{f}^{*}}\right) d F(\varepsilon)>1,
$$

where $\varepsilon\left(\varepsilon^{*}\right)$ is given in (51).

Equation (55) follows from the steady-state version of the asset pricing equation (42) for land when $p_{t}^{E}=s_{t} p_{t}^{h}>0$ is constant over time. The interpretation of condition (56) is as follows: The left side of (56) represents the benefit of buying one unit of aggregate land today and the right side represents the associated cost. In addition to the resale value of land, land commands a liquidity premium due to credit constraints. There are two components of the liquidity premium. First, the entrepreneur can sell a fraction $(1-\omega)$ of land to finance investment if his investment efficiency exceeds $\varepsilon_{f}^{*}$. Second, when his investment efficiency exceeds $\varepsilon_{f}^{* *}=\varepsilon\left(\varepsilon_{f}^{*}\right)$, he can borrow from banks using a fraction $\theta$ of his unsold land as collateral. This explains the two integral terms in (56). When the benefit exceeds the cost in the bubbleless steady state, entrepreneurs have incentives to trade land at a positive price, thereby creating a bubble.

Once the cutoff $\varepsilon_{b}^{*}$ is determined, we can follow a similar procedure to that described in the previous subsection to derive other steady state variables. The details can be found in the proof of Proposition 4 in Appendix A.

How do we relate our existence condition (56) to the traditional condition that the bubbleless steady-state interest rate must be lower than the rate of economic growth (Tirole (1985))? Unlike the OLG model of Tirole (1985), our model features credit constraints in the infinite-horizon DNK framework. We have the following result.

Proposition 5 Suppose that the assumptions in Proposition 2 hold so that there exists a bubbleless steady state with $R_{f}=R\left(\varepsilon_{f}^{*}\right)>1$, where $\varepsilon_{f}^{*}$ is the investment threshold. A necessary condition for the existence of a bubbly steady state with $R_{b}>1$ is

$$
\Pi>\max \left\{\beta+\frac{1 / s-\beta}{1-\omega+\theta \omega}, R_{f}\right\}>1 .
$$

This proposition shows that for a bubbly steady state to exist, the net inflation rate must be positive and sufficiently high and the gross real interest rate $R_{f} / \Pi$ must be less than the gross 
growth rate of the economy (which is 1). But these conditions are not sufficient as shown in the previous proposition.

Does monetary policy affect the existence condition for a bubbly steady state?

Proposition 6 The higher the inflation rate, the more likely a bubbly steady state can exist.

The intuition of this proposition is as follows. As shown in Proposition 3, an increase in the rate of inflation reduces an entrepreneur's real balance and hence his net worth and investment. To keep the aggregate investment rate equal to the depreciation rate in the bubbleless steady state, there must be more firms to make investment. Thus the investment threshold must fall or the Tobin's $\mathrm{Q}$ must rise, causing the liquidity premium to rise in the bubbleless steady state. This raises the benefit of trading land so that condition (56) is more likely to be satisfied for higher inflation.

As mentioned earlier, the assumption of the reserve requirement is critical. Without this assumption (i.e., $\lambda=0$ ), we would have superneutrality of money and inflation (or monetary policy) would have no effect on the condition for the existence of a bubble.

It is possible that (56) does not hold for low inflation so that only a bubbleless equilibrium can exist initially. The central bank can conduct an expansionary monetary policy by increasing money supply such that inflation rises to a permanently higher level. At this higher level, condition (56) holds so that a bubble can emerge. On the other hand, suppose that the economy is initially in the bubbly steady state. When the central bank reduces money supply such that inflation decreases to a permanently lower level at which condition (56) fails to hold, the asset bubble will collapse. This result is consistent with the conventional wisdom that an expansionary monetary policy can fuel a bubble and a contractionary monetary policy can prick a bubble. The key intuition comes from the balance sheet channel. Inflation caused by expansionary monetary policy reduces an entrepreneur's net worth and raises the liquidity premium, thereby raising his demand for the bubble asset.

We now conduct a comparative statics analysis based on the parameter values given in Section 5.1. We study the impact of the inflation target on the bubbly steady state when (56) holds. Figure 1 presents the result, which shows that higher inflation has a negative effect on the economy in the long run. It raises the size of the asset bubble, but lowers output, consumption, capital, and labor. The intuition is that higher inflation lowers the real balance and hence entrepreneurs' net worth, leading to lower investment. On the other hand, the credit-constrained entrepreneurs will demand more bubble assets to finance investment. In the meantime, higher inflation is associated with higher money supply, which can support a larger size of bubbles and inflate asset bubbles. As we discussed earlier, a larger size of the asset bubble has both intensive and extensive margin effects. It allows entrepreneurs to borrow more to make investment. But as the borrowing cutoff $\varepsilon_{t}^{* *}$ rises (see Figure 1), fewer firms will borrow and invest. The net effect leads to reduced aggregate investment and capital accumulation. 


\section{Dynamic Responses to Shocks}

In this section we study the dynamic responses of the model economy to various shocks. We shall focus on a bubbly steady state and local dynamics around the bubbly steady state. To provide quantitative experiments, we need to assignment parameter values.

\subsection{Calibration}

We calibrate our model at quarterly frequency so that the bubbly steady state is roughly consistent with the long-run behavior of the US economy. We assume that the investment-efficiency shock

follows a Pareto distribution with $F(\varepsilon)=1-\left(\varepsilon / \varepsilon_{\min }\right)^{-\frac{1}{\eta}}$. We set $\varepsilon_{\min }=1-\eta$ so that the unconditional mean is 1 . As is standard in the business cycle literature, we set $\alpha=0.33, \beta=0.99$, and $\delta=0.025$. We choose $\eta=0.33$ to match the aggregate investment-to-output ratio of 0.2 as in the data. We choose the utility weight on labor $\psi=3.36$ so that the average hours worked in the bubbly steady state equal $25 \%$ of the total time endowment. We set $\Pi=1.01$ so that the steady state annual inflation rate is $4 \%$, which is consistent with the average inflation rate during the period between 1975 and 2016. We set $\lambda=0.1$ so that the required reserve ratio is $10 \%$. As in the DNK literature (e.g., BGG (1999) and Gilchrist and Leahy (2002)), we set $\xi=0.75$ and $\sigma=11$, implying that the duration of price adjustments is 4 quarters and the steady-state markup is $\sigma /(1-\sigma)=1.1$.

We set $\omega=0.25$, which is in line with the ratio of inventory to the sum of existing home sales and inventory, according to the National Association of Retailer. A large literature using commercial mortgage data finds that the loan-to-value ratio is typically between $70 \%$ to $80 \%$. Thus we set $\theta=0.75$, meaning that entrepreneurs can borrow against $75 \%$ of the value of their existing real estate. We set the pledgeability parameter for capital $\mu=0.2$, which is consistent with the estimates reported in Liu, Wang, and Zha (2013) and Miao, Wang, and Xu (2015). The ratio of the commercial real estate value to output in the data is 2.6. As a baseline estimate, we suppose that about $30 \%$ of this ratio is due to bubbles. We then set $s=0.995$ such that $p^{h} / Y=0.84$ in the bubbly steady state. This means that new bubbles account for $0.5 \%$ of total bubbles. Our calibrated parameter values imply that the bubbly steady-state quarterly gross nominal deposit rate $R_{b}$ is 1.0039 and the bubbleless steady state quarterly nominal gross deposit rate $R_{f}$ is 1.0003 . All conditions in Proposition 4 are satisfied.

Now we assign parameter values for the shocks and the interest rate rules. As in the DNK literature (e.g., Galí (2008)), we set $\phi_{\pi}=1.5, \phi_{y}=0.5 / 4$, and $\phi_{p}=0$ in the Taylor rule (36). For the inflation targeting rule (37), we set $\phi_{p}=0, \phi_{\pi}=1.1$ (weak inflation targeting), and $\phi_{\pi}=2$ (strong inflation targeting), as in Bernanke and Gertler (1999) and Gilchrist and Leahy (2002). As baseline values, we set the persistence parameters in the monetary policy shock, technology shock, 
and sentiment shock as $\rho_{v}=0.5, \rho_{a}=0.9$, and $\rho_{s}=0.5$, respectively.

Similar to Galí (2014), our model implies a continuum of bubbly steady state indexed by $s$. In his unidimensional equilibrium system, Galí (2014) shows that there are two types of bubbly steady states: one is stable and the other is unstable. We are unable to derive this result theoretically for our multi-dimensional equilibrium system. We have verified numerically that the bubbly steady state is a saddle point for many values of $s$. Galí (2014) restricts his analysis to the stable steady state and views the bubble as a backward-looking predetermined variable that converges to the steady state starting at any initial value. He also introduces a sunspot shock to drive the dynamics of the bubble. By contrast, when the bubbly steady state is a saddle point, the bubble is a forwardlooking nonpredetermined variable and its initial value must be endogenously solved.

\subsection{Technology Shocks}

We start by analyzing the impact of a positive technology shock that raises $\varepsilon_{a t}$ by $1 \%$ initially. Figure 2 plots the impulse responses of some key variables and shows that consumption, investment, and output all rise on impact, but inflation and nominal interest rate decline on impact. The positive comovement of consumption, investment, and output is easy to understand as in the real business cycles literature. The negative responses of inflation and nominal interest rate follow the usual intuition in the DNK literature (e.g., Woodford (2003) and Galí (2008)). To see this, we log-linearize the equilibrium system around the non-stochastic bubbly steady state and derive the following New Keynesian Phillips curve ${ }^{13}$

$$
\hat{\Pi}_{t}=\frac{1}{\xi}(1-\xi)(1-\beta \xi) \hat{p}_{w t}+\beta E_{t} \hat{\Pi}_{t+1},
$$

where the marginal cost $\hat{p}_{w t}$ (the relative price of wholesale goods) satisfies

$$
\hat{p}_{w t}=\alpha \hat{R}_{k t}+(1-\alpha) \hat{w}_{t}-\hat{A}_{t}
$$

Following a positive technology shock, the marginal cost goes down or the markup (the inverse of the marginal cost) goes up. Thus inflation declines. The central bank's interest rate rule calls for a decline of the nominal interest rate by increasing money supply. Hours worked also decline due to price rigidities under the Taylor rule and the weak inflation targeting rule. For firms that do not adjust prices to meet their output demand, they have to reduce hours when facing a positive technology shock (see, e.g., Galí $(1999,2008)$ ). This negative effect can dominate depending on the parameter values in preferences, technology, and the interest rate rule. For the strong inflation targeting rule, labor actually rises because the real interest rate falls too much. This monetary policy rule causes consumption, investment, and output to have the largest rise on impact.

\footnotetext{
${ }^{13}$ We use hatted variable to denote the $\log$ deviation from the deterministic steady state. Appendix B presents the complete log-linearized equilibrium system.
} 
The special feature of our model is the response of the land price even though nothing changes in the asset fundamentals as the bubble asset (land) has no fundamental payoffs. To see the intuition, we can derive the log-linearized equation for the land price

$$
\begin{aligned}
\hat{p}_{t}^{h}= & E_{t} \hat{p}_{t+1}^{h}+\hat{C}_{t}-E_{t} \hat{C}_{t+1}+\hat{s}_{t}-s \beta \theta \omega\left[1-F\left(\varepsilon^{* *}\right)\right] \frac{\varepsilon^{* *}}{\varepsilon^{*}} E_{t} \hat{\varepsilon}_{t+1}^{* *} \\
& -s \beta\left[(1-\omega) \int_{\varepsilon^{*}}^{\varepsilon_{\max }} \frac{\varepsilon}{\varepsilon^{*}} d F(\varepsilon)+\theta \omega \frac{1}{\varepsilon^{*}} \int_{\varepsilon^{* *}}^{\varepsilon_{\max }}\left(\varepsilon-\varepsilon^{* *}\right) d F(\varepsilon)\right] E_{t} \hat{\varepsilon}_{t+1}^{*} .
\end{aligned}
$$

There are three factors that affect the land price: the stochastic discount factor (SDF) $\hat{C}_{t}-E_{t} \hat{C}_{t+1}$, the sentiment shock $\hat{s}_{t}$, and the liquidity premium. The liquidity premium has two components reflected by the last two terms in the equation above. Figure 2 shows that the two cutoffs $\hat{\varepsilon}_{t}^{*}$ and $\hat{\varepsilon}_{t}^{* *}$ fall on impact in response to a positive technology shock. Thus the liquidity premium rises. The SDF also rises because consumption growth declines. Both components cause the land price to rise on impact. Note that the land bubble $p_{t}^{h}$ or $\hat{p}_{t}^{h}$ is a forward-looking variable and its initial value must be endogenously determined. Our discussions on the movements of the land bubble follow the conventional wisdom on any asset prices.

The fall of $\varepsilon_{t}^{*}$ is due to the rise of the capital price $q_{t}^{k}$ as $\varepsilon_{t}^{*}=1 / q_{t}^{k}$, which in turn is driven by the rise in the marginal revenue product of capital $R_{k t}$ following a positive technology shock. The fall of $\varepsilon_{t}^{* *}$ is due to the fall of the lending rate $R_{l t}$. When the nominal deposit rate $R_{t}$ falls, $R_{l t}$ must fall by (12), which is derived by the zero-profit condition of banks. Thus real bank lending $L_{t+1} / P_{t}$ rises, helping the increase in investment. Note that money supply $\left(g_{t}\right)$ increases in the short run in order to support the lower nominal deposit rate and higher bank lending.

\subsection{Monetary Policy Shocks}

Next we consider the impact of an expansionary monetary policy shock when $v_{t}$ or $\varepsilon_{v t}$ drops by 25 basis points initially in (36) and (37). This corresponds to a one percentage point drop of the annual nominal rate on impact holding other variables fixed. Figure 3 displays the impulse responses. We find that the (quarterly) nominal interest rate $R_{t}$ initially drops by less than 25 basis points because the interest rate endogenously responds to changes in output and inflation by the Taylor rule (36) and expected inflation by the inflation targeting rule (37).

The traditional transmission mechanism of monetary policy is through the interest rate channel. When prices are sticky, the real rate falls and thus consumption rises following an expansionary monetary policy shock. This can be seen from the log-linearized equation of (24):

$$
\hat{C}_{t}=E_{t} \hat{C}_{t+1}-\left(\hat{R}_{t}-E_{t} \hat{\Pi}_{t+1}\right)+\frac{R \beta}{\Pi} \int_{\varepsilon^{*}}^{\varepsilon_{\max }} \frac{\varepsilon}{\varepsilon^{*}} d F(\varepsilon) E_{t} \hat{\varepsilon}_{t+1}^{*} .
$$

This is analogous to the dynamic IS curve in the traditional DNK model, with an additional liquidity premium term. The fall of the real rate also causes the increase in investment and hence output. Thus monetary policy is not neutral in the DNK framework. 
In addition to this interest rate channel, our model features a lending channel and an asset price channel. An expansionary monetary policy causes money supply to increase in the short run and hence lending through the banking system rises. The lending rate $R_{l t}$ falls as the deposit rate $R_{t}$ falls. This in turn raises investment. This is similar to the lending channel discussed in BGG (1999). A unique feature of our model is that asset prices rise for the following three reasons. First, the increased bank lending calls for more collateral from firms. This raises the land price since a fixed fraction of land is used as collateral. Second, the SDF rises on impact because consumption rises initially and gradually declines. Third, both components of the liquidity premium rise in response to an expansionary monetary policy shock. As Figure 3 shows, both cutoffs $\varepsilon_{t}^{*}$ and $\varepsilon_{t}^{* *}$ fall on impact. The intuition is the following. Since consumption, investment, and output rise as discussed earlier, labor demand must also rise on impact as capital is predetermined. The real wage rate rises by the labor supply condition (6). By the labor demand condition (40), the marginal cost or the relative price of wholesale goods $p_{w t}$ must rise, causing inflation to rise. Moreover, it follows from equation (41) that the marginal revenue product of capital $R_{k t}$ must rise, causing the capital

price $q_{t}^{k}$ to rise. As a result, the liquidity premium rises or the investment cutoff $\varepsilon_{t}^{*}$ falls, and hence the lending cutoff $\varepsilon_{t}^{* *}$ falls too by (12) and (22) when $R_{t}$ falls.

The increased asset price raises entrepreneurs' net worth and collateral value, allowing entrepreneurs to finance more investment. Both the intensive and extensive margin effects work in the same direction so that the asset price channel provides a large amplification effect on investment. As shown in Figure 3, investment rises by about 1-2\% on impact in response to a cut of 25 basis points of the nominal deposit rate.

Our result that an expansionary monetary policy by cutting interest rates leads to an increase in asset bubbles on impact is different from that in Galí (2014). Galí (2014) focuses on the stable steady state in his unidimensional equilibrium system and assumes that the asset bubble is predetermined and hence its initial size is independent of monetary policy. By contrast, the asset bubble in our paper is a forward-looking nonpredetermined variable so that both its initial size and growth rate are determined by the real interest rate. The initial jump of the asset bubble provides an important amplification mechanism for monetary policy.

\subsection{Sentiment Shocks}

Suppose that agents suddenly become more optimistic in that there is a positive sentiment shock that raises $\varepsilon_{s t}$ by $0.5 \%$ initially. As Figure 4 shows, this shock immediately raises the land price by the asset pricing equation, thereby raising entrepreneurs' net worth and collateral value. Thus bank lending and investment rise, inducing output to rise. Labor must rise on impact because output rises and capital is predetermined. The increased bank lending causes money supply and inflation to rise. The initial rise of inflation is quantitatively small. The nominal deposit rate must 
rise due to the interest rate rules. Since prices are sticky, the real deposit rate rises and hence households have an incentive to save instead of consuming. For the Taylor rule in (36), the real interest rate rises so much that consumption falls on impact. Thus there is no comovement between consumption and investment in response to a positive sentiment shock. This seems counterintuitive because asset prices do not have a wealth effect on households, but this is a special feature of our model in which households do not hold land in equilibrium. In Miao and Wang (2015b) and Miao, Wang, and $\mathrm{Xu}$ (2015) we show that introducing endogenous capital utilization can amplify the initial impact on output and hence can allow consumption to rise. For the inflation targeting rule in (37), the nominal interest rate does not respond to output directly so that the rise of the real interest rate is smaller, causing consumption to rise on impact. This effect is stronger for the strong inflation targeting rule.

Increased investment generates more capital accumulation and hence the capital price $q_{t}^{k}$ falls on impact. Consequently the investment cutoff $\varepsilon_{t}^{*}=1 / q_{t}^{k}$ rises and the lending cutoff $\varepsilon_{t}^{* *}$ also rises. This implies that fewer firms make investment. But this negative extensive margin effect is dominated by the positive intensive margin effect so that aggregate investment rises. The net effect on investment is relatively small: a $1 \%$ increase in the land price only raises aggregate investment by about $0.1 \%$ on impact. In the meantime, the liquidity premium falls on impact, but this negative effect on the land price is dominated by the direct effect of the positive sentiment shock.

Note that Figure 4 shows that the asset bubble declines over time, but the real interest rate is still positive. This is because the initial sentiment shock dies out over time so that the path of the asset bubble follows that of the shock by (57). The initial jump of the asset bubble roughly reflects the cumulative effect of the initial sentiment shock, $\varepsilon_{s 0} /\left(1-\rho_{s}\right)=1 \%$.

In summary, the non-fundamental sentiment shock can drive large movements of the asset bubble due to its forward-looking nature. But it has a small positive impact on the real economy and generates mild inflation. The main reason is that the opposite intensive and extensive margin effects partially offset each other and mitigate the impact of a sentiment shock on aggregate demand and the real economy.

\section{Should Monetary Policy Respond to Asset Bubbles?}

In the previous section we have shown how asset bubbles and other macroeconomic variables respond to various exogenous shocks when monetary policy does not respond to asset bubbles. In this section we address the question whether monetary policy should respond to asset bubbles.

We consider the Taylor rule in (36) by fixing the parameters $\phi_{\pi}=1.5$ and $\phi_{y}=0.125$. We also consider the weak inflation targeting rule and strong inflation targeting rule by fixing $\phi_{\pi}=1.1$ and $\phi_{\pi}=2$ in (37). We turn off the monetary policy shock by setting $v_{t}=0$. We search for the weight $\phi_{p}$ to maximize the unconditional mean of household utility in (4) in response to each of the 


\begin{tabular}{lllll}
\hline Monetary Policy Rules & \multicolumn{2}{c}{ Sentiment Shock } & TFP shock \\
\cline { 2 - 5 } & weight $\phi_{p}$ & gain $\Omega(\%)$ & weight $\phi_{p}$ & gain $\Omega(\%)$ \\
\hline$\hat{R}_{t}=1.5 \hat{\Pi}_{t}+0.125 \hat{Y}_{t}+\phi_{p} \hat{p}_{h t}$ & -0.36 & 2.45 & -0.27 & 0.34 \\
$\hat{R}_{t}=1.1 E_{t} \hat{\Pi}_{t+1}+\phi_{p} \hat{p}_{h t}$ & -0.03 & 0.05 & -0.03 & 0.35 \\
$\hat{R}_{t}=2 E_{t} \hat{\Pi}_{t+1}+\phi_{p} \hat{p}_{h t}$ & -0.03 & 0.00 & -0.03 & 0.00 \\
\hline
\end{tabular}

Table 1: Optimal weights on asset bubbles and welfare gains.

two types of shocks to sentiment and TFP. ${ }^{14}$ We set the persistence parameters for these shocks as $\rho_{s}=0.5$ and $\rho_{a}=0.9$, and set the standard deviations as $\sigma_{s}=0.5 \%$ and $\sigma_{a}=1 \%$. Table 1 presents the optimal weights $\phi_{p}$ on asset bubbles and the welfare gains from optimally responding to asset bubbles.

The welfare gains are computed as follows. Let $\left\{C_{t}\right\}$ and $\left\{N_{t}\right\}$ denote the equilibrium consumption and labor processes for $\phi_{p}=0$. Let $V$ and $V^{*}$ denote the unconditional means of household utility when monetary policy does not respond and responds to asset bubbles, respectively. Then the welfare gains $\Omega$ in terms of consumption increase satisfies the equation

$$
E \sum_{t=0}^{\infty} \beta^{t}\left[\ln (1+\Omega) C_{t}-\psi N_{t}\right]=V^{*} .
$$

Solving yields $\Omega=\exp \left((1-\beta)\left(V^{*}-V\right)\right)-1$.

Table 1 shows that the welfare gain is equal to $2.45 \%$ increase in consumption for monetary policy to respond to asset bubbles under the interest rate rule in (36), when facing the sentiment shock. The weight on asset bubbles is equal to -0.36 . The welfare gains are small for all other cases. They are close to zero for the strong inflation targeting rule.

Figure 5 presents unconditional expected household utility as a function of the weight $\phi_{p}$ under the Taylor-type rule in (36) and the weak inflation targeting rule in (37) with $\phi_{\pi}=1.1$. The top left panel shows that expected utility is a decreasing function of $\phi_{p}$ when agents face only the sentiment shock. Note that the Blanchard-Kahn condition is violated for $\phi_{p}$ smaller than -0.36 . The top right panel shows that expected utility is a hump-shaped function of $\phi_{p}$ and the BlanchardKahn condition is violated for $\phi_{p}$ smaller than -0.34 . The bottom two panels show that expected utility all decrease with $\phi_{p}$ and the Blanchard-Kahn condition is violated for $\phi_{p}$ smaller than -0.03 .

To understand the intuition, Figure 6 presents the impulse responses to a positive TFP shock for three cases under the interest rate rule in (36): (i) monetary policy optimally responds to asset bubbles; (ii) monetary policy does not respond to asset bubbles; and (iii) prices are flexible with $\phi_{p}=0$. In the flexible price equilibrium, consumption, investment, output, and labor all comove in response to a positive technology shock. But when prices are sticky and $\phi_{p}=0$, labor falls. To

\footnotetext{
${ }^{14}$ We use the second-order approximation method to compute the welfare gains implemented by Dynare (Adjemian et al (2011)).
} 
correct this inefficiency, monetary policy should respond to the rising asset bubble by cutting the nominal interest rate by setting $\phi_{p}=-0.27$. In this way the rise of the asset bubble is larger so that bank lending rises more, mitigating the fall of inflation. The Taylor-type interest rate rule also calls for cutting the nominal interest rate in response to a decline of inflation. Thus the real interest rate falls. In the meantime, the asset price and bank lending channels cause investment and output to rise more. This allows consumption to rise more and labor to rise instead of falling. Overall, the impulse responses of consumption, investment, output, and labor under the optimal simple rule are closer to those in the flexible price equilibrium.

Figure 7 presents impulse responses to a positive sentiment shock under the interest rate rule (36). We find that consumption, investment, output, and labor all increase in response to a positive sentiment shock under the optimal simple rule $\left(\phi_{p}=-0.36\right)$. Without responding to the asset bubble, consumption falls because the real interest rate rises (also see Figure 4). Moreover, the impact of the sentiment shock on the real economy and inflation is very small for the both the sticky price and flexible price equilibria. Under the optimal simple rule, the central bank should cut the nominal interest rate so that the real interest rate falls and consumption rises, thereby raising household utility. In the meantime, the asset bubble rises more on impact. As Figures 6 and 7 show, our model is different from Galí's (2014) in which the asset bubble does not move on impact. In our model the initial rise of the bubble improves allocation efficiency by raising aggregate investment and output.

Figure 8 shows that, under the Taylor-type rule (36), the inflation volatility increases with $\phi_{p}$ conditional on the TFP shock and is a U-shaped function of $\phi_{p}$ conditional on the sentiment shock. For both cases, the bubble volatility decreases with $\phi_{p}$. Thus the 'leaning against the wind' interest rate policy will reduce the bubble volatility, but it may come at the cost of raising the inflation volatility. This is in sharp contrast to Galí's (2014) result that such a policy may raise the bubble volatility conditional on the sentiment shock. The intuition is that a larger $\phi_{p}$ reduces the initial response of the bubble to either a TFP shock or a sentiment shock as the bubble is a forwardlooking variable. ${ }^{15}$ This reduces aggregate demand more and causes a larger drop of inflation from the target in response to a positive TFP shock, so that the inflation volatility is higher conditional on the TFP shock. In response to a positive sentiment shock, a larger negative $\phi_{p}$ lowers nominal interest rates more and raises aggregate demand more, thereby generating a larger rise of inflation relative to the target. But a larger positive $\phi_{p}$ raises nominal interest rates more and reduces aggregate demand more, thereby generating a larger drop of inflation relative to the target. For both cases the inflation volatility is higher conditional on the sentiment shock.

Will the preceding results change if the central bank adopts the inflation targeting rule in (37)?

\footnotetext{
${ }^{15}$ For space limitation, we have not reported the figures for the impact of $\phi_{p}$ on the impulse response functions. Such results may be foreshadowed from Figures 6 and 7 .
} 
Table 1 shows that the optimal weights on the asset bubble are similar and approximately equal to $\phi_{p}=-0.03$ for all cases. The welfare gains are very small for the strong inflation targeting rule, but are nonnegligible ( $0.35 \%$ increase in consumption) for the weak inflation targeting rule in response to a TFP shock. Under the inflation targeting rule, the nominal interest rate does not respond to output changes and hence is more accommodative to economic growth. Thus consumption can rise in response to a positive sentiment shock due to the small change in the real interest rate and labor can rise in response to a positive TFP shock due to the fall of the real interest rate, as shown in Figures 2 and 4. This means that the distortion caused by price stickiness is less severe, especially for the strong inflation targeting rule. Thus the welfare gains are very small for the strong inflation targeting rule. ${ }^{16}$ Our results confirm the early finding of Bernanke and Gertler (1999).

\section{Discussions}

In our model deposits are money (or M1) and households do not hold money in equilibrium because the return on deposits is too low around the steady state. Moreover, there is no cash in our model. We can adopt several approaches in monetary economics (e.g., Chari, Christiano, and Eichenbaum (1995), Einarsson and Marquis (2001), and Galí (2014)) to allow households to hold money including deposits and cash in equilibrium. For example, we could introduce cash-in-advance constraints and deposit-in-advance constraints. We could also simply introduce cash or deposits in the utility function because they provide some services other than "storage of wealth."

For simplicity, we ignore cash and introduce deposits in the utility function as follows

$$
E_{0} \sum_{t=0}^{\infty} \beta^{t}\left(\ln C_{t}-\psi N_{t}+\chi \ln \left(\frac{S_{a, t+1}}{P_{t}}\right)\right)
$$

where $\chi>0$. In this case aggregate investment satisfies

$$
I_{t}=\left(R_{k t} K_{t}+\frac{m_{t}}{\Pi_{t}}-\frac{s_{a t} R_{t-1}}{\Pi_{t}}+(1-\omega) p_{t}^{h}\right)\left(1-F\left(\varepsilon_{t}^{*}\right)\right)+\left(\theta \omega p_{t}^{h}+\mu K_{t}\right)\left(1-F\left(\varepsilon_{t}^{* *}\right)\right),
$$

where $s_{a t+1} \equiv S_{a, t+1} / P_{t}$ denotes household real deposits. Since banks have to pay interest to household deposits, the funds available for aggregate investment is reduced by $s_{a t} R_{t-1} / \Pi_{t}$ relative to equation (45). The conditions for the existence of bubbleless and bubbly steady states are too complicated to permit a complete characterization. For example, one has to subtract $s_{a} R / \Pi$ in the first parenthesis of equation (53). Thus the bubbleless steady-state cutoff becomes smaller. But we need additional equations to pin down this cutoff because $s_{a}$ is endogenous.

For the bubbly steady state, we can still prove the statement that there is a unique solution for the bubbly steady state cutoff to equation (55) if and only if condition (56) holds as in Proposition

\footnotetext{
${ }^{16}$ Regarding the impact of $\phi_{p}$ on the inflation and bubble volatilities under the inflation targeting rule (37), we find a figure similar to Figure 8 and hence will not report it here.
} 
4. But this is not sufficient to pin down the bubbly steady state for the reason discussed above. We need numerical methods to solve the model. We use numerical examples to illustrate the intuition by varying $\chi>0$ and fixing other parameter values as in Section 5.1. We find that the bubble size is larger when $\chi>0$ is larger. In this case, households prefer to save more in banks, banks can make more loans, and repayments to households are also higher. Inefficient firms have more funds to buy bubbles and efficient firms can sell bubbles at a higher price to repay loans. The increased bubble size is used partly to repay household deposits so that real investment, consumption, and output barely change.

We also find that impulse responses are qualitatively similar for $\chi>0$ and $\chi=0$. The key difference is that household saving $s_{a, t+1}$ responds to shocks. In particular, $s_{a, t+1}$ falls in response to a positive TFP shock or an expansionary monetary policy shock because the real interest rate

falls. But $s_{a, t+1}$ rises in response to a sentiment shock because the real interest rate rises. The movements of $s_{a, t+1}$ can amplify the shocks.

For another extension, it is straightforward to introduce long-run growth to our model as in Tirole (1985), Galí (2014), Miao and Wang (2015b), and Miao, Wang, and Xu (2015). With a positive economic growth rate, the bubbly and bubbleless steady-state real interest rates can be positive. Since such an analysis is standard, we will not provide the details here.

\section{Conclusion}

We have presented an infinite-horizon model of rational asset bubbles in the DNK framework. We have studied how monetary policy affects asset bubbles in the steady state and their dynamics in response to fundamental and non-fundamental shocks. We have also studied whether central banks should respond to asset bubbles. We hope our model can deepen our understanding of the relation between monetary policy and asset bubbles. Many of our results are different from those in Galí's (2014) OLG model. We think modeling the interaction between financial frictions and asset bubbles is key to understanding the differences. Moreover, whether asset bubbles are treated as a forward-looking or backward-looking variable is critical for understanding their dynamics. Some of our results confirm the early finding of Bernanke and Gertler $(1999,2001)$ and provide a theoretical foundation for the conventional wisdom on the role of monetary policy in managing asset bubbles. In terms of future research, it would be interesting to study the issue of liquidity trap. The present paper focuses on local dynamics around a bubbly steady state. Dong, Miao, and Wang (2016) show that the economy can enter a liquidity trap with interest rates at the zero lower bound after bubbles collapse. It would also be interesting to enrich our model to confront with the data along the lines of Ikeda (2013) and Miao, Wang, and Xu (2015). Finally, doing empirical work on the relation between monetary policy and asset bubbles along the lines of Galí and Gambetti (2015) and Brunnermeier and Schnabel (2015) should be important. 


\section{References}

Adjemian, Stéphane, Houtan Bastani, Michel Juillard, Frédéric Karamé, Ferhat Mihoubi, George Perendia, Johannes Pfeifer, Marco Ratto and Sébastien Villemot. 2011. Dynare: Reference Manual, Version 4. Dynare working papers, 1. CEPREMAP.

Aoki, Kosuke, and Kalin Nikolov, 2015, Bubbles, Banks and Financial Stability, Journal of Monetary Economics 74, 33-51.

Asriyan, Vladimir, Luca Fornaro, Alberto Martin, and Jaume Ventura, 2016, Monetary policy for a Bubbly World, NBER working paper, w22639.

Bernanke, Ben S. and Mark Gertler, 1999, Monetary Policy and Asset Price Volatility, in New Challenges for Monetary Policy, Federal Reserve Bank of Kansas City, 77-128.

Bernanke, Ben S. and Mark Gertler, 2001, Should Central Banks Respond to Movements in Asset Prices?" American Economic Review 91, 253-257.

Bernanke, Ben S., Mark Gertler, and Simon Gilchrist, 1999, Financial Accelerator in a Quantitative Business Cycle Framework, In: J. Taylor, M. Woodford (eds.), Handbook of Macroeconomics, Elsevier Science, Amsterdam.

Blanchard, Olivier, David Romer, Michael Spence, and Joseph Stiglitz, 2012, In the Wake of the Crisis, MIT Press Cambridge, MA.

Borio, Claudio EV, Neale Kennedy, and Stephen David Prowse, 1994, Exploring Aggregate Asset Price Fluctuations across Countries: Measurement, Determinants and Monetary Policy Implications, Bank for International Settlements, Monetary and Economic Department.

Borio, Claudio, and Philip Lowe, 2002, Asset Prices, Financial and Monetary Stability: Exploring the Nexus, BIS Working Papers no. 114.

Brunnermeier, Markus K., and Isabel Schnabel, 2015, Bubbles and Central Banks: Historical Perspectives, working paper, Princeton University.

Caballero, Ricardo J., and Arvind Krishnamurthy, 2006, Bubbles and Capital Flow Volatility: Causes and Risk Management. Journal of Monetary Economics 53, 35-53.

Calvo, Guillermo A., 1983, Staggered Prices in a Utility-Maximizing Framework, Journal of Monetary Economics 12, 383-398.

Cecchetti, Stephen G., Hans Gensberg, John Lipsky and Sushil Wadhwani, 2000, Asset Prices and Central Bank Policy, Geneva Reports on the World Economy 2, CEPR.

Chari, V.V., Lawrence J. Christiano and Martin Eichenbaum, 2015, Inside Money, Outside Money, and Short-Term Interest Rates, Journal of Money, Credit and Banking 27, Part 2: Liquidity, Monetary Policy, and Financial Intermediation, 1354-1386.

Dong, Feng, Jianjun Miao, and Pengfei Wang, 2016, Asset Bubbles and Liquidity Traps, work in progress, Boston University.

Einarsson, Tor, and Milton H. Marquis, 2001, Bank Intermediation over the Business Cycle, Journal of Money, Credit and Banking 33, 876-899

Erceg, Christopher J., Dale W. Henderson, and Andrew T. Levin, 2000, Optimal Monetary Policy with Staggered Wage and Price Contracts, Journal of Monetary Economics 46, 281-313. 
European Central Bank (ECB), 2010, Asset Price Bubbles and Monetary Policy Revisited, Monthly Bulletin, November, 71-83.

Farhi, Emmanuel, and Jean Tirole, 2012, Bubbly Liquidity, Review of Economic Studies 79, 678706.

Galí, Jordi, 1999, Technology, Employment, and the Business Cycle: Do Technology Shocks Explain Aggregate Fluctuations?, The American Economic Review, 89(1), 249-265.

Galí, Jordi, 2008, Monetary Policy, Inflation, and the Business Cycle: An Introduction to the New Keynesian Framework, Princeton University Press.

Galí, Jordi, 2014, Monetary Policy and Rational Asset Price Bubbles, The American Economic Review 104, 721-752.

Galí, Jordi, and Luca Gambetti, 2015, The Effects of Monetary Policy on Stock Market Bubbles: Some Evidence, The American Economic Journal: Macroeconomics, 7(1), 233-257.

Gilchrist, Simon, and John V. Leahy, 2002, Monetary Policy and Asset Prices, Journal of Monetary Economics, 49(1), 75-97.

Greenspan, Alan, 2015, Comments and Discussion, Brookings Papers on Economic Activity, Spring, 197-206.

Hirano, Tomohiro, and Noriyuki Yanagawa, 2013, Asset Bubbles, Endogenous Growth and Financial Frictions, working paper, University of Tokyo.

Ikeda, Daisuke, 2013, Monetary Policy and Inflation Dynamics in Asset Price Bubbles, working paper, Bank of Japan.

Issing, Otmar, 2009, Asset Process and Monetary Policy, Cato J, 29, 45.

Jordà, Òscar, Mortiz Schularick, and Alan M. Taylor, 2015, Leveraged Bubbles, Journal of Monetary Economics 76, S1-S20.

Kiyotaki, Nobuhiro, and John Moore, 1997, Credit Cycles, Journal of Political Economy 105, $211-48$.

Kiyotaki, Nobuhiro, and John Moore, 2008, Liquidity, Business Cycles and Monetary Policy, working paper, Princeton University.

Kocherlakota, Narayana, 2009, Bursting Bubbles: Consequences and Cures, working paper, University of Minnesota.

Liu, Zheng, Pengfei Wang, and Tao Zha, 2013, Land-Price Dynamics and Macroeconomic Fluctuations, Econometrica, 81(3), 1147-1184.

Martin, Alberto, and Jaume Ventura, 2012, Economic Growth with Bubbles, American Economic Review 102, 3033-3058.

Martin, Alberto, and Jaume Ventura, 2015, The International Transimission of Credit Bubbles: Theory and Policy. Journal of Monetary Economics 76, S37-S56.

Miao, Jianjun, 2014, Introduction to Economic Theory of Bubbles, Journal of Mathematical Economics 53, 130-136. 
Miao, Jianjun, and Pengfei Wang, 2012, Bubbles and Total Factor Productivity, American Economic Review 102, 82-87.

Miao, Jianjun, and Pengfei Wang, 2014, Sectoral Bubbles, Misallocation, and Endogenous Growth, Journal of Mathematical Economics 53, 153-163.

Miao, Jianjun, and Pengfei Wang, 2015a, Banking Bubbles and Financial Crises, Journal of Economic Theory 157, 763-792.

Miao, Jianjun, and Pengfei Wang, 2015b, Bubbles and Credit Constraints, working paper, Boston University.

Miao, Jianjun, Pengfei Wang, and Zhiwei Xu, 2015, A Bayesian DSGE Model of Stock Market Bubbles and Business Cycles, Quantitative Economics 6, 599-635.

Miao, Jianjun, Pengfei Wang, and Lifang Xu, 2016, Stock Market Bubbles and Unemployment, Economic Theory 61, 273-307.

Miao, Jianjun, Pengfei Wang, Tao Zha, 2014, Liquidity Premia, Price-Rent Dynamics, and Business Cycles, NBER working paper, w20377.

Miao, Jianjun, Pengfei Wang, and Jing Zhou, 2015, Asset Bubbles, Collateral, and Policy Analysis, Journal of Monetary Economics 76, S57-S70.

Miao, Jianjun, Pengfei Wang, and Jing Zhou, 2016, Asset Bubbles and Foreign Interest Rate Shocks, working paper, Boston University.

Samuelson, Paul A., 1958, An Exact Consumption-loan Model of Interest with or without the Social Contrivance of Money, Journal of Political Economy 66, 467-482.

Santos, Manuel S., and Michael Woodford, 1997, Rational Asset Pricing Bubbles, Econometrica $65,19-58$.

Shiller, Robert, J., 1981, Do Stock Prices Move Too Much to be Justified by Subsequent Changes in Dividends? American Economic Review 71, 421-436.

Schularick, Moritz and Alan M. Taylor, 2012, Credit Booms Gone Bust: Monetary Policy, Leverage Cycles and Financial Crises, 1870-2008, American Economic Review 102, 1029-1061.

Tirole, Jean, 1985, Asset Bubbles and Overlapping Generations, Econometrica 53, 1499-1528.

Wang, Pengfei and Yi Wen, 2012, Speculative Bubbles and Financial Crisis, American Economic Journal Macroeconomics 4, 184-221.

Woodford, Michael, 2003, Interest Rate and Prices: Foundation of a Theory of Monetary Policy, Princeton University Press, Princeton, NJ. 

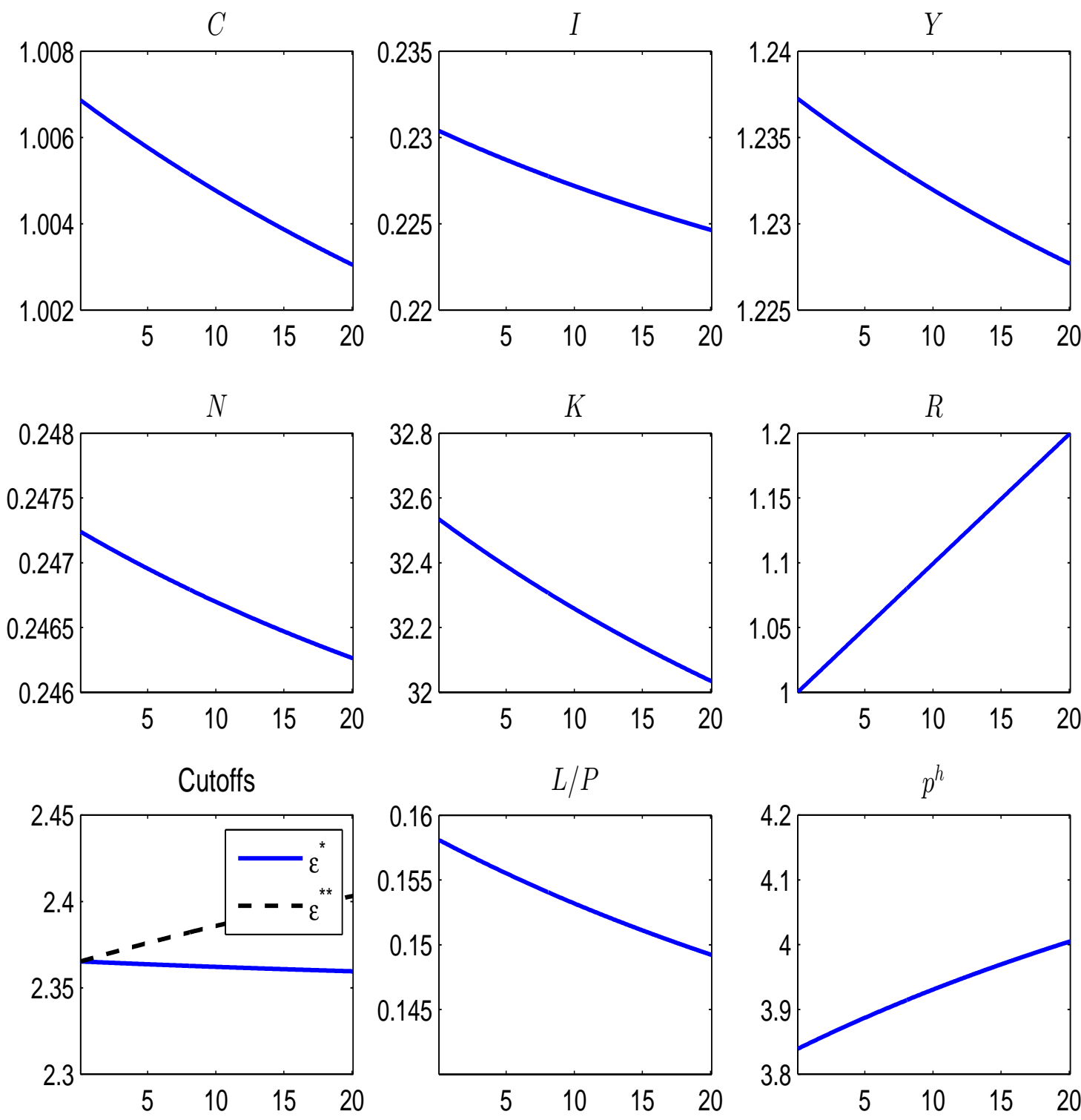

$(\Pi-1) * 100$

$(\Pi-1) * 100$

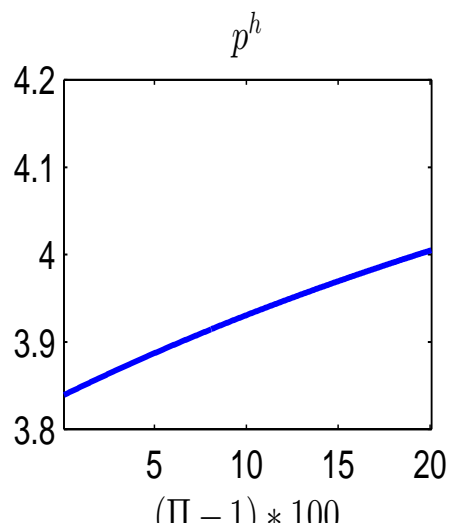

Figure 1: Comparative statics for the bubbly steady state. Parameter values are given in Section 5.1 . 

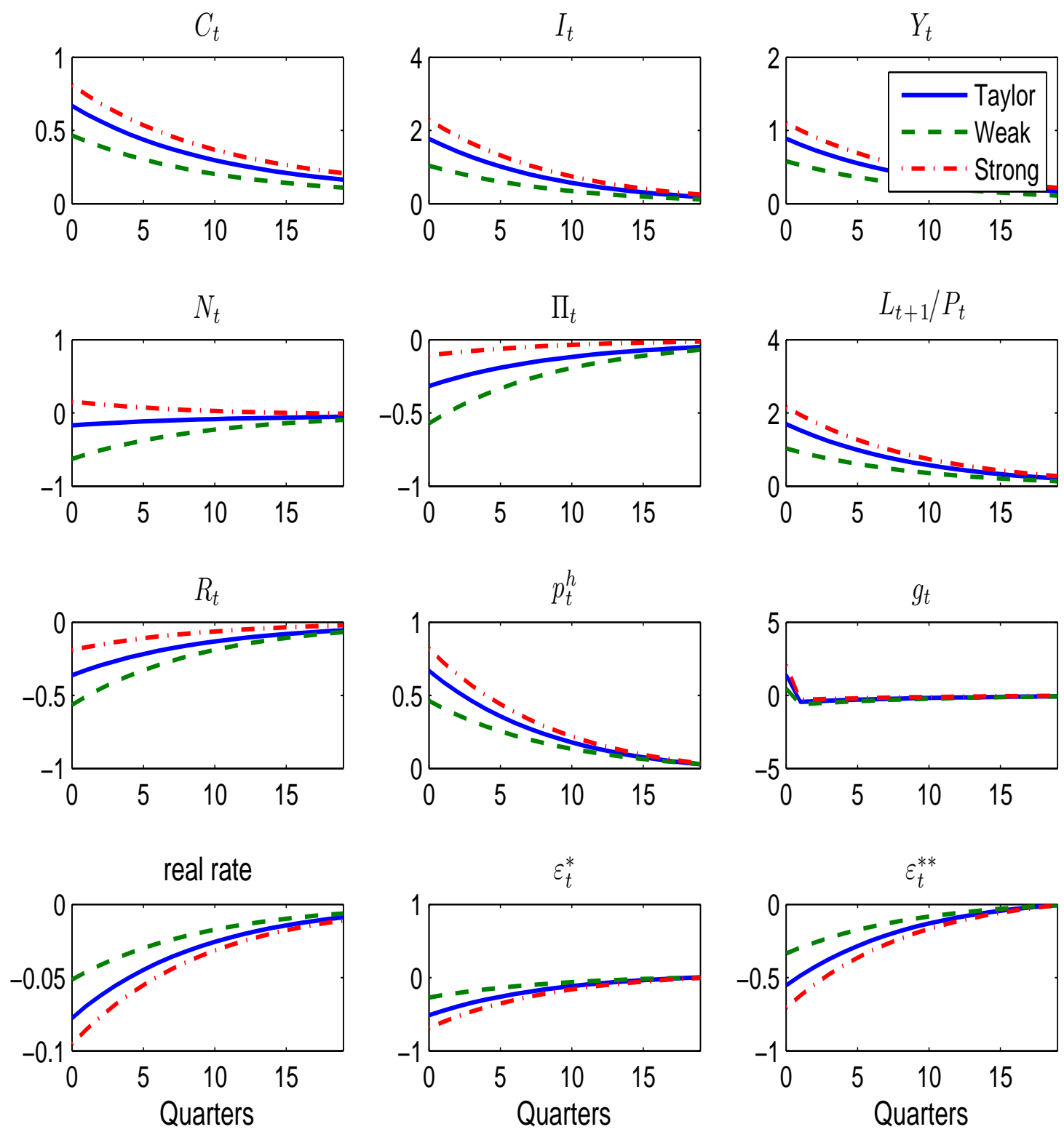

Figure 2: Impulse responses to a positive 1\% technology shock. All vertical axes are measured in percentage. The solid, dashed, and dot dashed lines represent responses under the Taylor rule in (36), the weak inflation targeting rule in (37) with $\phi_{\pi}=1.1$, and the strong inflation targeting rule in (37) with $\phi_{\pi}=2$. In all these rules, $\phi_{p}=0$. 

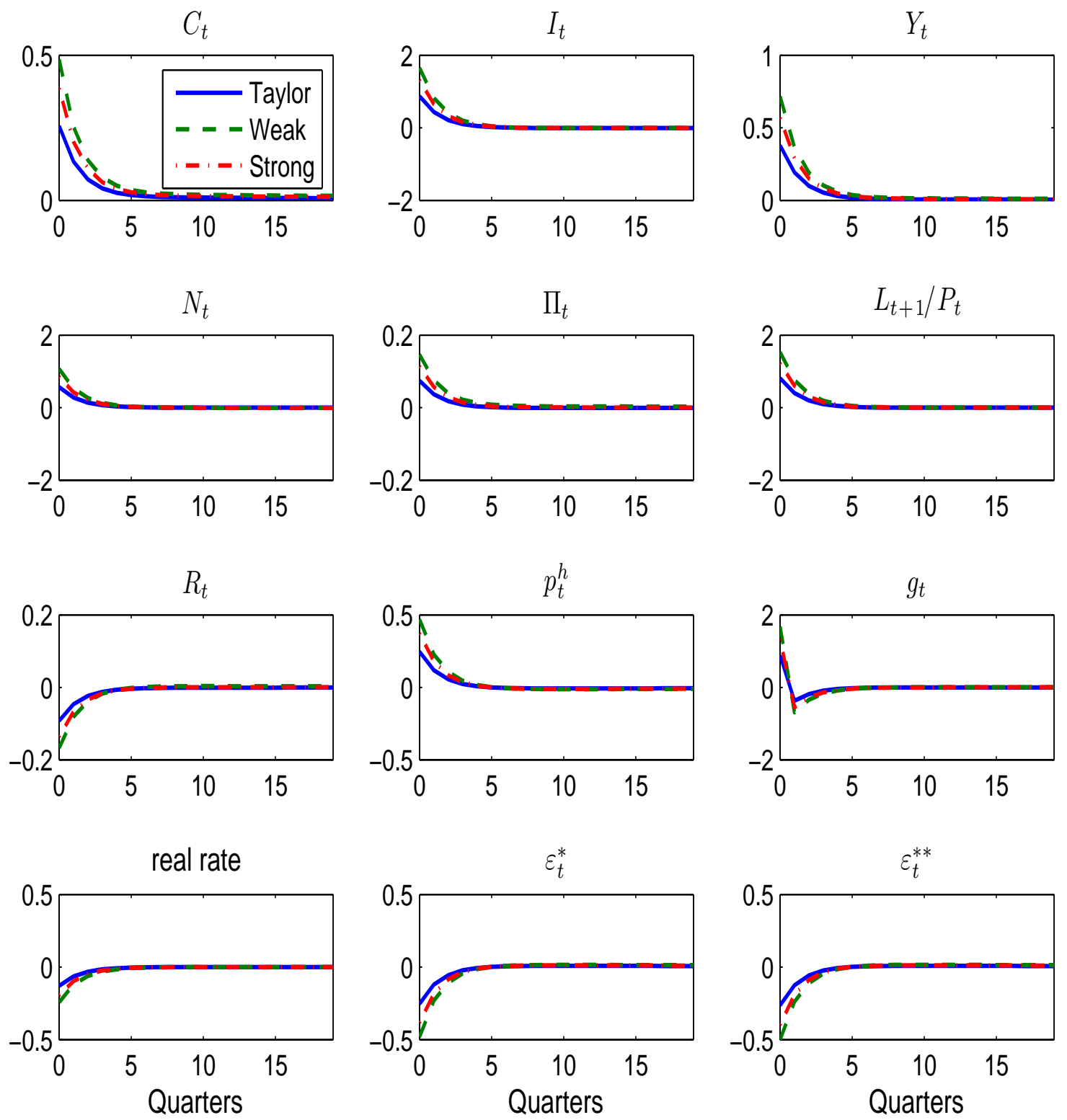

Figure 3: Impulse responses to a negative $0.25 \%$ shock to the nominal interest rate. All vertical axes are measured in percentage. The solid, dashed, and dot dashed lines represent responses under the Taylor rule in (36), the weak inflation targeting rule in (37) with $\phi_{\pi}=1.1$, and the strong inflation targeting rule in (37) with $\phi_{\pi}=2$. In all these rules, $\phi_{p}=0$. 

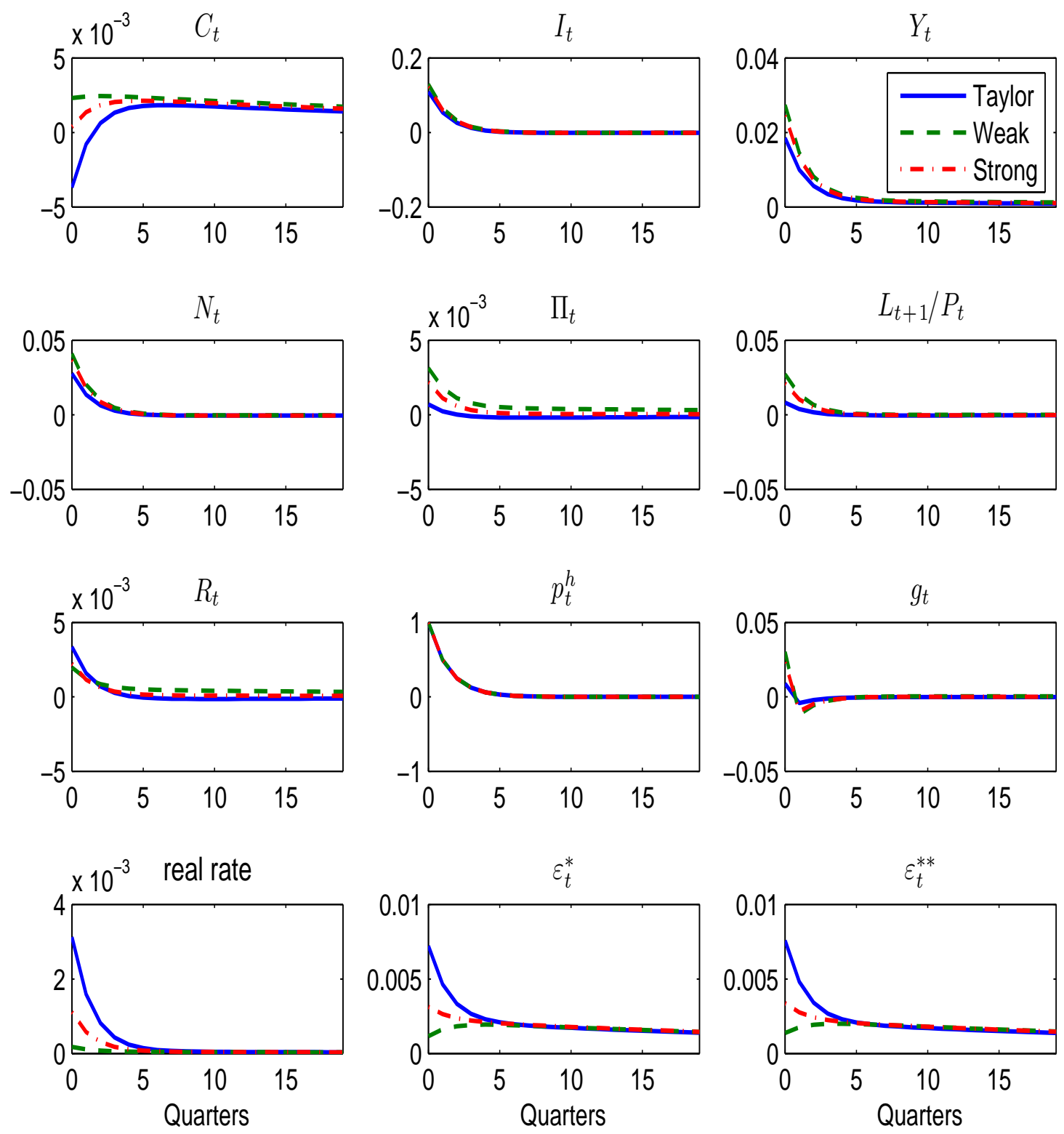

Figure 4: Impulse responses to a positive $0.5 \%$ shock to the sentiment. All vertical axes are measured in percentage. The solid, dashed, and dot dashed lines represent responses under the Taylor rule in (36), the weak inflation targeting rule in (37) with $\phi_{\pi}=1.1$, and the strong inflation targeting rule in (37) with $\phi_{\pi}=2$. In all these rules, $\phi_{p}=0$. 

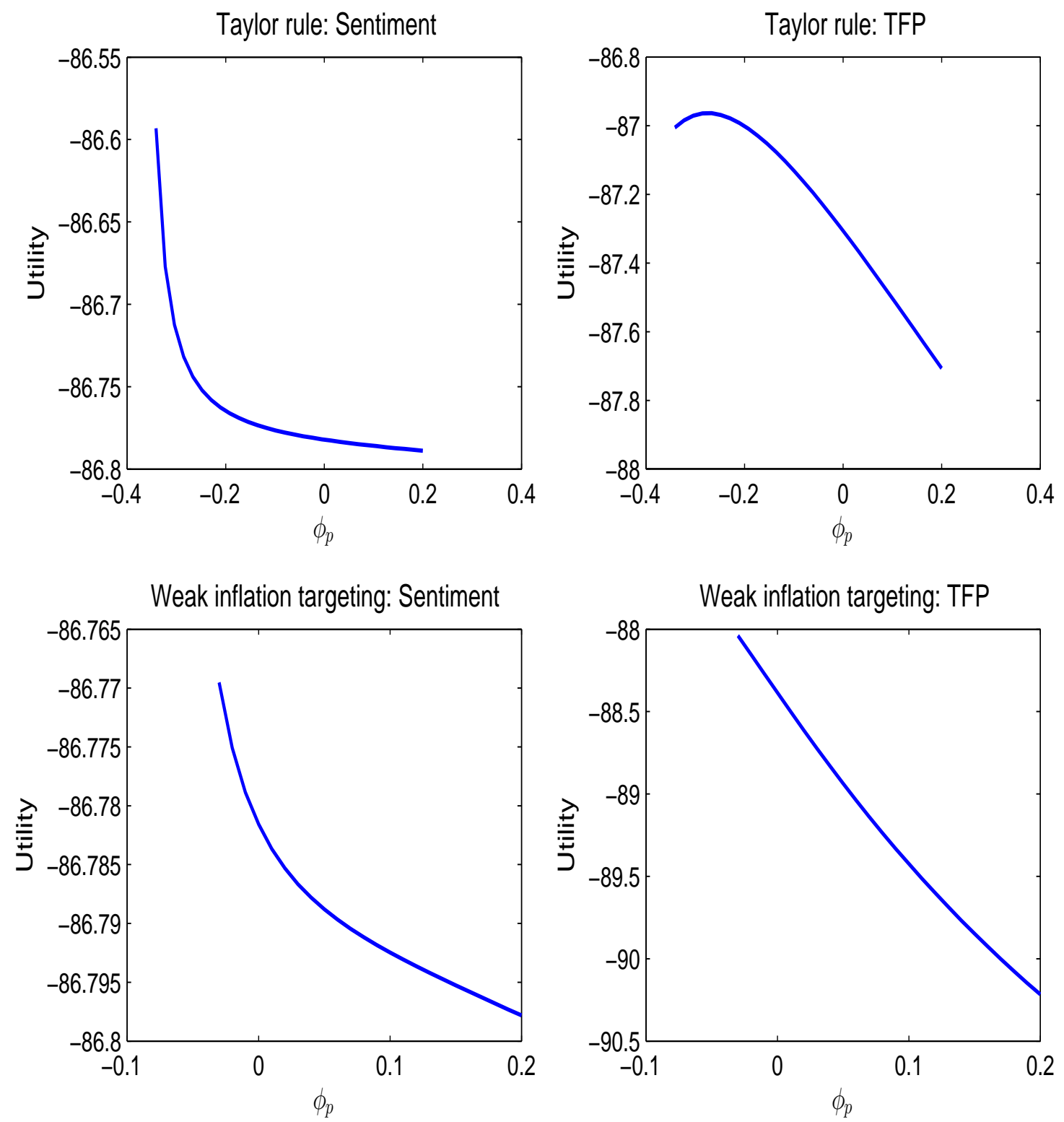

Figure 5: Unconditional expected household utility as a function of the weight $\phi_{p}$ on the asset bubble when only sentiment shocks or TFP shocks are turned on. The top two panels are for the interest rate rule in (36) with $\phi_{\pi}=1.5$ and $\phi_{y}=0.125$. The bottom two panels are for the weak inflation targeting rule in (37) with $\phi_{\pi}=1.1$. 

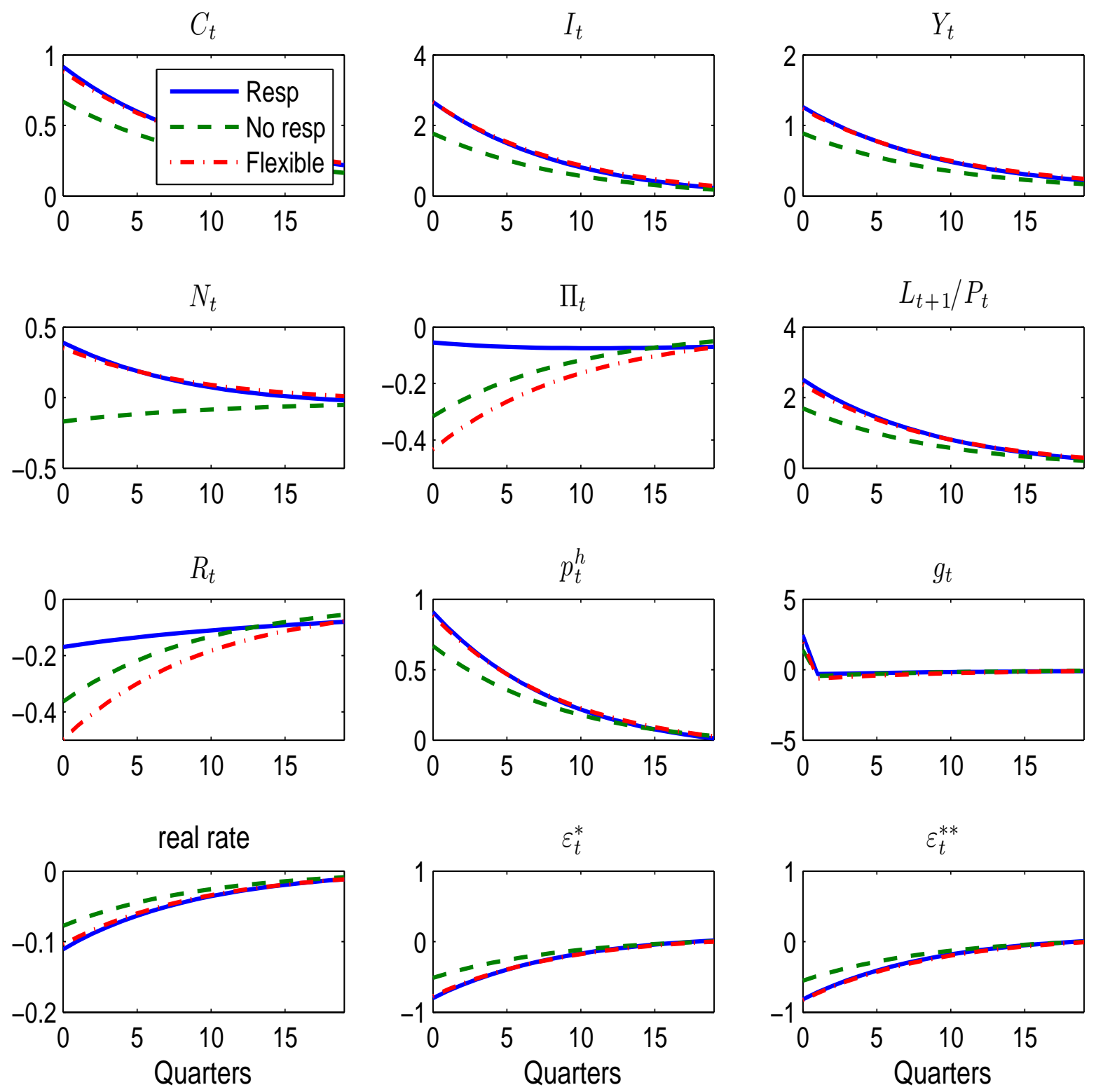

Figure 6: Impulse responses to a positive 1\% TFP shock under the interest rate rule in (36). All vertical axes are measured in percentage. The solid lines represent the case with the optimal weight on asset bubbles given in Table 1 . The dashed lines represent the case with $\phi_{p}=0$. The dot dashed lines represent the responses in the flexible price equilibrium 

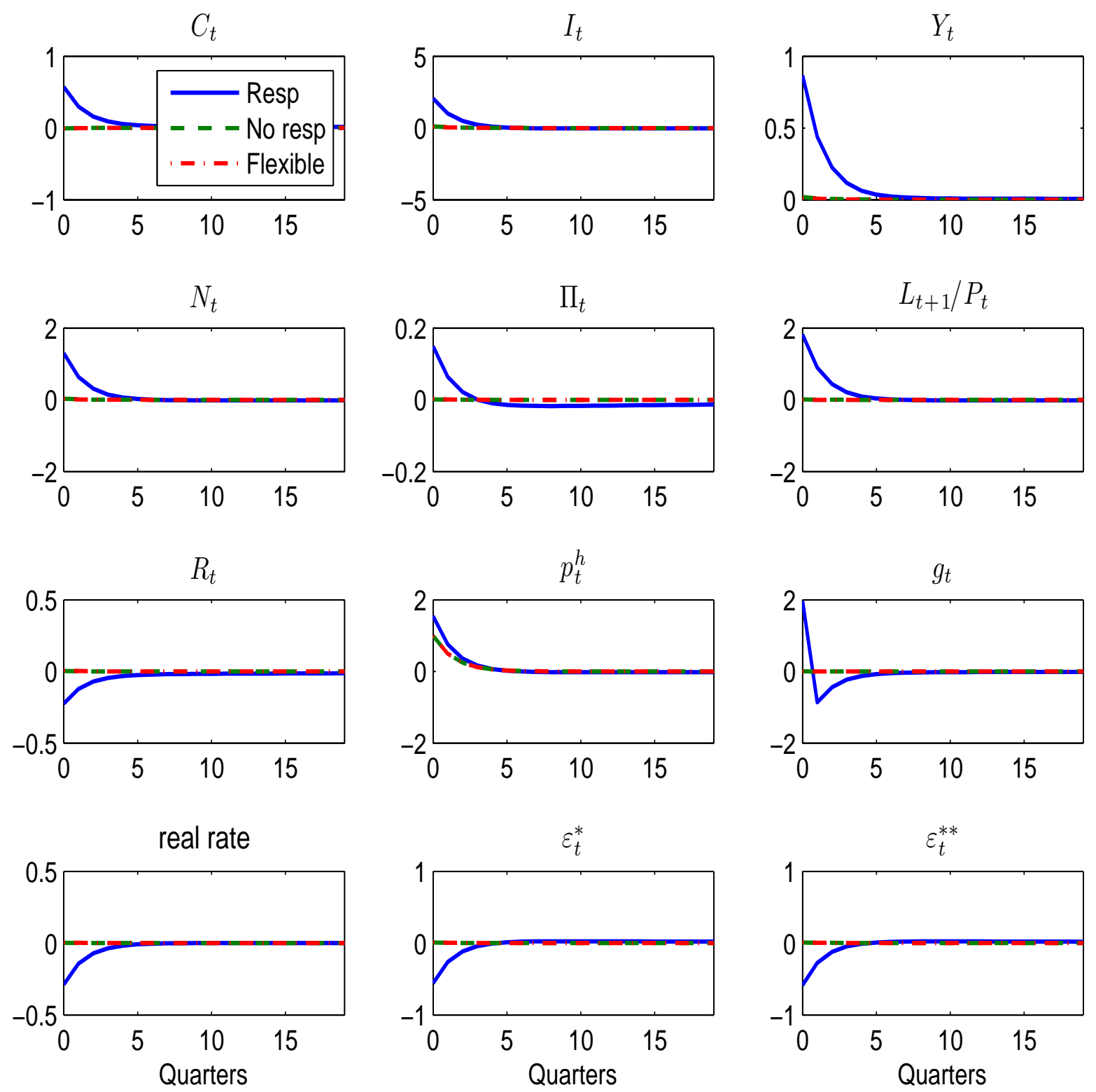

Figure 7: Impulse responses to a positive 0.5\% sentiment shock under the interest rate rule in (36). All vertical axes are measured in percentage. The solid lines represent the case with the optimal weight on asset bubbles given in Table 1 . The dashed lines represent the case with $\phi_{p}=0$. The dot dashed lines represent the responses in the flexible price equilibrium 

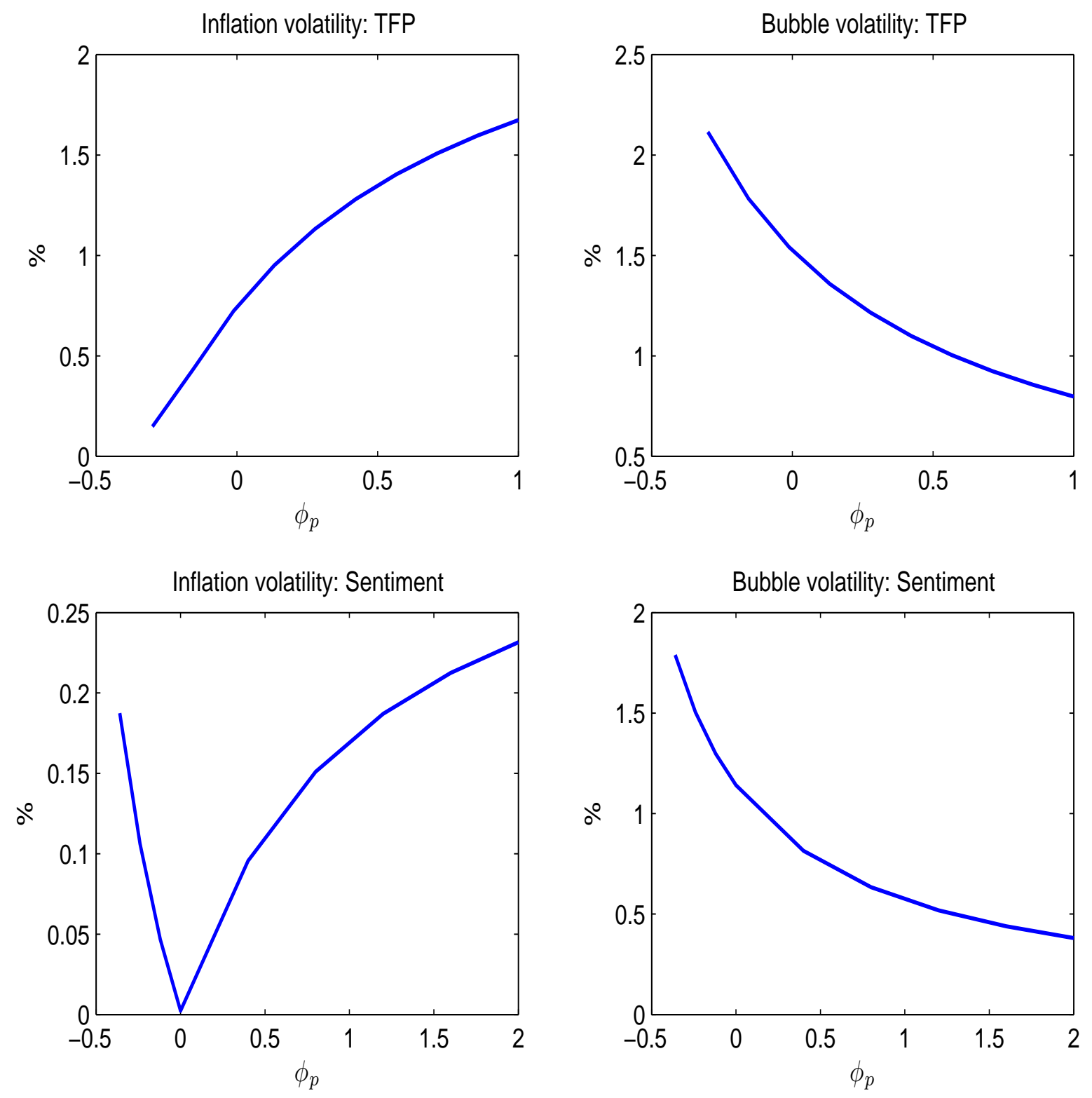

Figure 8: The inflation and output volatilities as functions of $\phi_{p}$ under the Taylor-type rule in (36) when only sentiment shocks or TFP shocks are turned on. 


\section{Appendix}

\section{A Proofs}

Proof of Proposition 1: We conjecture that the value function takes the following form

$$
\begin{aligned}
& V_{t}\left(K_{j t}, S_{j t}, L_{j t},\left\{H_{j, t \mid t-k}\right\}_{k=0}^{\infty}, \varepsilon_{j t}\right) \\
= & \phi_{t}^{k}\left(\varepsilon_{j t}\right) K_{j t}+\phi_{t}^{s}\left(\varepsilon_{j t}\right) S_{j t}-\phi_{t}^{l}\left(\varepsilon_{j t}\right) L_{j t}+\sum_{k=0}^{\infty} \phi_{t \mid t-k}^{h}\left(\varepsilon_{j t}\right) H_{j, t \mid t-k},
\end{aligned}
$$

where $\phi_{t}^{i}\left(\varepsilon_{j t}\right), i \in\{k, s, l, h\}$, satisfy

$$
\begin{aligned}
q_{t}^{k} & =\beta E_{t} \frac{\Lambda_{t+1}}{\Lambda_{t}} \int \phi_{t+1}^{k}(\varepsilon) d F(\varepsilon), \\
\frac{1}{P_{t}} & =\beta E_{t} \frac{\Lambda_{t+1}}{\Lambda_{t}} \int \phi_{t+1}^{s}(\varepsilon) d F(\varepsilon), \\
\frac{R_{l t}}{R_{t}} \frac{1}{P_{t}} & =\beta E_{t} \frac{\Lambda_{t+1}}{\Lambda_{t}} \int \phi_{t+1}^{l}(\varepsilon) d F(\varepsilon), \\
p_{t \mid t-k}^{h} & =\beta E_{t} \frac{\Lambda_{t+1}}{\Lambda_{t}} \int \phi_{t+1 \mid t-k}^{h}(\varepsilon) d F(\varepsilon) .
\end{aligned}
$$

By convention, we set $H_{j, t \mid t}=\frac{\delta_{h}}{1-\delta_{h}}$.

Substituting (15), (18), and the above conjecture into the Bellman equation (20), we obtain

$$
\begin{aligned}
& V_{t}\left(K_{j t}, S_{j t}, L_{j t},\left\{H_{j, t \mid t-k}\right\}_{k=0}^{\infty}, \varepsilon_{j t}\right) \\
= & \max _{I_{j t}, S_{j t+1}, L_{j t+1}, H_{j t+1}} R_{k t} K_{j t}-I_{j t}+\frac{1}{P_{t}}\left(S_{j t} R_{t-1}-S_{j t+1}+L_{j t+1}-L_{j t} R_{l t-1}\right) \\
& +\left(1-\delta_{h}\right) \sum_{k=0}^{\infty} p_{t \mid t-k}^{h} H_{j, t \mid t-k}-\sum_{k=0}^{\infty} p_{t \mid t-k}^{h} H_{j, t+1 \mid t-k} \\
& +q_{t}^{k}\left((1-\delta) K_{j t}+\varepsilon_{j t} I_{j t}\right)+\frac{1}{P_{t}} S_{j t+1}-\frac{R_{l t}}{R_{t}} \frac{1}{P_{t}} L_{j t+1}+\sum_{k=0}^{\infty} p_{t \mid t-k}^{h} H_{j, t+1 \mid t-k} \\
= & \max _{I_{j t}, S_{j t+1}, L_{j t+1}}\left(R_{k t}+q_{t}^{k}(1-\delta)\right) K_{j t}+\frac{R_{t-1}}{P_{t}} S_{j t}-\frac{R_{l t-1}}{P_{t}} L_{j t} \\
& +\left(1-\delta_{h}\right) \sum_{k=0}^{\infty} p_{t \mid t-k}^{h} H_{j, t \mid t-k}+\left(q_{t}^{k} \varepsilon_{j t}-1\right) I_{j t}-\frac{1}{P_{t}}\left(\frac{R_{l t}}{R_{t}}-1\right) L_{j t+1} .
\end{aligned}
$$

Since $I_{j t} \geq 0$ and $D_{j t} \geq 0$, it follows from (A.6) that $I_{j t}=0$ if $\varepsilon_{j t}<1 / q_{t}^{k} \equiv \varepsilon_{t}^{*}$, but the firm makes as much investment as possible so that $D_{j t}=0$ if $\varepsilon_{j t}>\varepsilon_{t}^{*}$. Therefore, when $\varepsilon_{j t} \geq 1 / q_{t}^{k} \equiv \varepsilon_{t}^{*}$, it follows from (18) that

$$
\begin{aligned}
I_{j t}= & R_{k t} K_{j t}+\frac{S_{j t} R_{t-1}-S_{j t+1}+L_{j t+1}-L_{j t} R_{l t-1}}{P_{t}} \\
& +\left(1-\delta_{h}\right) \sum_{k=0}^{\infty} p_{t \mid t-k}^{h} H_{j, t \mid t-k}-\sum_{k=0}^{\infty} p_{t \mid t-k}^{h} H_{j, t+1 \mid t-k} .
\end{aligned}
$$


Using this investment rule, we can simplify (A.6) for $\varepsilon_{j t}<\varepsilon_{t}^{*}$ as

$$
\begin{aligned}
& V_{t}\left(K_{j t}, S_{j t}, L_{j t},\left\{H_{j, t \mid t-k}\right\}_{k=0}^{\infty}, \varepsilon_{j t}\right) \\
= & \max _{L_{j t+1}}\left(R_{k t}+q_{t}^{k}(1-\delta)\right) K_{j t}+\frac{R_{t-1}}{P_{t}} S_{j t}-\frac{R_{l t-1}}{P_{t}} L_{j t} \\
& +\left(1-\delta_{h}\right) \sum_{k=0}^{\infty} p_{t \mid t-k}^{h} H_{j, t \mid t-k}-\frac{1}{P_{t}}\left(\frac{R_{l t}}{R_{t}}-1\right) L_{j t+1} .
\end{aligned}
$$

Given $R_{l t}>R_{t}$, we have $L_{j t+1}=0$. Therefore, when $\varepsilon_{j t}<\varepsilon_{t}^{*}$, equation (A.8) becomes

$$
\begin{aligned}
& V_{t}\left(K_{j t}, S_{j t}, L_{j t},\left\{H_{j, t \mid t-k}\right\}_{k=0}^{\infty}, \varepsilon_{j t}\right) \\
= & \left(R_{k t}+q_{t}^{k}(1-\delta)\right) K_{j t}+\frac{R_{t-1}}{P_{t}} S_{j t}-\frac{R_{l t-1}}{P_{t}} L_{j t}+\left(1-\delta_{h}\right) \sum_{k=0}^{\infty} p_{t \mid t-k}^{h} H_{j, t \mid t-k} .
\end{aligned}
$$

Matching coefficients in (A.1) and (A.9), we have

$$
\begin{aligned}
\phi_{t}^{k}\left(\varepsilon_{j t}\right) & =R_{k t}+q_{t}^{k}(1-\delta), \phi_{t \mid t-k}^{h}\left(\varepsilon_{j t}\right)=\left(1-\delta_{h}\right) p_{t \mid t-k}^{h}, \\
\phi_{t}^{s}\left(\varepsilon_{j t}\right) & =\frac{R_{t-1}}{P_{t}}, \phi_{t}^{l}\left(\varepsilon_{j t}\right)=\frac{R_{l t-1}}{P_{t}}
\end{aligned}
$$

for $\varepsilon_{j t}<\varepsilon_{t}^{*}$.

Next consider the case of $\varepsilon_{j t} \geq \varepsilon_{t}^{*}=1 / q_{t}^{k}$. Substituting (A.7) into (A.6) yields

$$
\begin{aligned}
& V_{t}\left(K_{j t}, S_{j t}, L_{j t},\left\{H_{j, t \mid t-k}\right\}_{k=0}^{\infty}, \varepsilon_{j t}\right) \\
= & \max _{S_{j t+1}, L_{j t+1}, H_{j t+1}}\left(R_{k t}+q_{t}^{k}(1-\delta)\right) K_{j t}+\frac{R_{t-1}}{P_{t}} S_{j t}-\frac{R_{l t-1}}{P_{t}} L_{j t}+\left(1-\delta_{h}\right) \sum_{k=0}^{\infty} p_{t \mid t-k}^{h} H_{j, t \mid t-k} \\
& +\left(q_{t}^{k} \varepsilon_{j t}-1\right)\left(R_{k t} K_{j t}+\frac{S_{j t} R_{t-1}-S_{j t+1}+L_{j t+1}-L_{j t} R_{l t-1}}{P_{t}}\right)-\frac{1}{P_{t}}\left(\frac{R_{l t}}{R_{t}}-1\right) L_{j t+1} \\
& +\left(q_{t}^{k} \varepsilon_{j t}-1\right)\left[\left(1-\delta_{h}\right) \sum_{k=0}^{\infty} p_{t \mid t-k}^{h} H_{j, t \mid t-k}-\sum_{k=0}^{\infty} p_{t \mid t-k}^{h} H_{j, t+1 \mid t-k}\right] \\
= & \max _{j t+1}, L_{j t+1}, H_{j t+1}\left(R_{k t}+\left(q_{t}^{k} \varepsilon_{j t}-1\right) R_{k t}+q_{t}^{k}(1-\delta)\right) K_{j t}+\left(1+\left(q_{t}^{k} \varepsilon_{j t}-1\right)\right) \frac{R_{t-1}}{P_{t}} S_{j t} \\
& -\left(1+\left(q_{t}^{k} \varepsilon_{j t}-1\right)\right) \frac{R_{l t-1}}{P_{t}} L_{j t}+\left(1+\left(q_{t}^{k} \varepsilon_{j t}-1\right)\right)\left(1-\delta_{h}\right) \sum_{k=0}^{\infty} p_{t \mid t-k}^{h} H_{j, t \mid t-k} \\
& -\left(q_{t}^{k} \varepsilon_{j t}-1\right) S_{j t+1}-\frac{1}{P_{t}}\left(\frac{R_{l t}}{R_{t}}-q_{t}^{k} \varepsilon_{j t}\right) L_{j t+1}-\left(q_{t}^{k} \varepsilon_{j t}-1\right) \sum_{k=0}^{\infty} p_{t \mid t-k}^{h} H_{j, t+1 \mid t-k} .
\end{aligned}
$$

Thus we must have $S_{j t+1}=0$ and

$$
H_{j, t+1 \mid t-k}=\omega\left(1-\delta_{h}\right) H_{j, t \mid t-k}, \quad k=0,1,2, \ldots
$$

Moreover, using (17) gives

$$
\frac{L_{j t+1}}{P_{t}}= \begin{cases}0, & \text { if } \varepsilon_{j t}<\varepsilon_{t}^{* *} \\ \theta \omega\left(1-\delta_{h}\right) \sum_{k=0}^{\infty} p_{t \mid t-k}^{h} H_{j, t \mid t-k}+\mu K_{j t}, & \text { otherwise }\end{cases}
$$


where we define

$$
\varepsilon_{t}^{* *} \equiv \frac{R_{l t}}{R_{t} q_{t}^{k}}=\frac{R_{l t}}{R_{t}} \varepsilon_{t}^{*}
$$

Since $R_{l t}>R_{t}, \varepsilon_{t}^{* *}>\varepsilon_{t}^{*}$.

Using the preceding decision rules, we can derive that

$$
\begin{aligned}
& V_{t}\left(K_{j t}, S_{j t}, L_{j t},\left\{H_{j, t \mid t-k}\right\}_{k=0}^{\infty}, \varepsilon_{j t}\right) \\
= & \left(R_{k t}+\left(q_{t}^{k} \varepsilon_{j t}-1\right) R_{k t}+q_{t}^{k}(1-\delta)\right) K_{j t}+\left(1+\left(q_{t}^{k} \varepsilon_{j t}-1\right)\right) \frac{R_{t-1}}{P_{t}} S_{j t} \\
& -\left(1+\left(q_{t}^{k} \varepsilon_{j t}-1\right)\right) \frac{R_{l t-1}}{P_{t}} L_{j t}+\left(1+\left(q_{t}^{k} \varepsilon_{j t}-1\right)\right)\left(1-\delta_{h}\right) \sum_{k=0}^{\infty} p_{t \mid t-k}^{h} H_{j, t \mid t-k} \\
& +\frac{q_{t}^{k}}{P_{t}}\left(\theta \omega P_{t}^{h} H_{j t}+P_{t} \mu K_{j t}\right) \max \left\{\varepsilon_{j t}-\varepsilon_{t}^{* *}, 0\right\} \\
& -\left(q_{t}^{k} \varepsilon_{j t}-1\right) \omega\left(1-\delta_{h}\right) \sum_{k=0}^{\infty} p_{t \mid t-k}^{h} H_{j, t \mid t-k},
\end{aligned}
$$

for $\varepsilon_{j t} \geq \varepsilon_{t}^{*}$.

Matching coefficients in (A.1) and (A.16) yields

$$
\begin{gathered}
\phi_{t}^{k}\left(\varepsilon_{j t}\right)=R_{k t}+\left(q_{t}^{k} \varepsilon_{j t}-1\right) R_{k t}+q_{t}^{k}(1-\delta)+\max \left\{\varepsilon_{j t}-\varepsilon_{t}^{* *}, 0\right\} q_{t}^{k} \mu \\
=\left(1+\left(\frac{\varepsilon_{j t}}{\varepsilon_{t}^{*}}-1\right)\right) R_{k t}+q_{t}^{k}(1-\delta)+\max \left\{\varepsilon_{j t}-\varepsilon_{t}^{* *}, 0\right\} q_{t}^{k} \mu \\
\phi_{t}^{s}\left(\varepsilon_{j t}\right)=\left(1+\left(q_{t}^{k} \varepsilon_{j t}-1\right)\right) \frac{R_{t-1}}{P_{t}}=\left(1+\left(\frac{\varepsilon_{j t}}{\varepsilon_{t}^{*}}-1\right)\right) \frac{R_{t-1}}{P_{t}} \\
\phi_{t}^{l}\left(\varepsilon_{j t}\right)=\left(1+\left(q_{t}^{k} \varepsilon_{j t}-1\right)\right) \frac{R_{l t-1}}{P_{t}}=\left(1+\left(\frac{\varepsilon_{j t}}{\varepsilon_{t}^{*}}-1\right)\right) \frac{R_{l t-1}}{P_{t}}, \\
\frac{\phi_{t}^{h}\left(\varepsilon_{j t}\right)}{1-\delta_{h}}=\left(1+\left(q_{t}^{k} \varepsilon_{j t}-1\right)\right) p_{t \mid t-k}^{h}+\theta \omega q_{t}^{k} p_{t \mid t-k}^{h} \max \left\{\varepsilon_{j t}-\varepsilon_{t}^{* *}, 0\right\}-\left(q_{t}^{k} \varepsilon_{j t}-1\right) p_{t \mid t-k}^{h} \omega \\
=\left(1+(1-\omega)\left(\frac{\varepsilon_{j t}}{\varepsilon_{t}^{*}}-1\right)\right) p_{t \mid t-k}^{h}+\theta \omega q_{t}^{k} p_{t \mid t-k}^{h} \max \left\{\varepsilon_{j t}-\varepsilon_{t}^{* *}, 0\right\}
\end{gathered}
$$

for $\varepsilon_{j t} \geq \varepsilon_{t}^{*}$.

Combining the above two cases, we deduce that, for any $\varepsilon_{j t} \in\left(\varepsilon_{\min }, \varepsilon_{\max }\right)$, we have

$$
\begin{gathered}
\phi_{t}^{k}\left(\varepsilon_{j t}\right)=\left(1+\max \left(\frac{\varepsilon_{j t}}{\varepsilon_{t}^{*}}-1,0\right)\right) R_{k t}+q_{t}^{k}(1-\delta)+\max \left\{\varepsilon_{j t}-\varepsilon_{t}^{* *}, 0\right\} q_{t}^{k} \mu, \\
\phi_{t}^{s}\left(\varepsilon_{j t}\right)=\left(1+\max \left(\frac{\varepsilon_{j t}}{\varepsilon_{t}^{*}}-1,0\right)\right) \frac{R_{t-1}}{P_{t}}, \\
\phi_{t}^{l}\left(\varepsilon_{j t}\right)=\left(1+\max \left(\frac{\varepsilon_{j t}}{\varepsilon_{t}^{*}}-1,0\right)\right) \frac{R_{l t-1}}{P_{t}}, \\
\frac{\phi_{t}^{h}\left(\varepsilon_{j t}\right)}{1-\delta_{h}}=\left(1+(1-\omega) \max \left(\frac{\varepsilon_{j t}}{\varepsilon_{t}^{*}}-1,0\right)\right) p_{t \mid t-k}^{h}+\theta \omega q_{t}^{k} p_{t \mid t-k}^{h} \max \left\{\varepsilon_{j t}-\varepsilon_{t}^{* *}, 0\right\} .
\end{gathered}
$$

Substituting the preceding four equations into (A.2)-(A.5) yields (23), (24), (25) in the proposition. Q.E.D. 
Proof of Lemma 1: Define the function

$$
G(z)=\int_{\varepsilon_{\min }}^{\varepsilon_{\max }} \max (\varepsilon, z) d F(\varepsilon)-\frac{\Pi}{\beta} z=0, z \in\left[\varepsilon_{\min }, \varepsilon_{\max }\right] .
$$

Note that $G^{\prime}(z)=F(z)-\frac{\Pi}{\beta}<0, G\left(\varepsilon_{\min }\right)=E[\varepsilon]-\frac{\Pi}{\beta} \varepsilon_{\min }>0$, and $G\left(\varepsilon_{\max }\right)=\varepsilon_{\max }-\frac{\Pi}{\beta} \varepsilon_{\max }<0$ by assumption 1. The intermediate value theorem ensures that there exists a unique solution for $\underline{\varepsilon} \in\left(\varepsilon_{\min }, \varepsilon_{\max }\right)$ to the equation in the lemma. Q.E.D.

Proof of Proposition 2: In any steady state, we can use (12) and (50) to derive that

$$
\varepsilon^{* *}=\frac{R_{l}}{R} \varepsilon^{*}=\frac{1-\frac{\lambda}{R\left(\varepsilon^{*}\right)}}{1-\lambda} \varepsilon^{*}=\frac{\varepsilon^{*}-\frac{\lambda \beta}{\Pi} \int_{\varepsilon_{\min }}^{\varepsilon_{\max }} \max \left(\varepsilon^{*}, \varepsilon\right) d F(\varepsilon)}{1-\lambda} .
$$

By assumption 1 and $\lambda \in(0,1)$, we can show that

$$
\frac{d \varepsilon^{* *}}{d \varepsilon^{*}}=\frac{1-\frac{\lambda \beta}{\Pi} F\left(\varepsilon^{*}\right)}{1-\lambda}>0
$$

Thus $\varepsilon^{* *}=\varepsilon\left(\varepsilon^{*}\right)$ increases with $\varepsilon^{*}$. We need the following result.

Lemma 2 For a sufficiently small $\mu, R_{k}\left(\varepsilon^{*}\right)$ decreases with $\varepsilon^{*}$ for $\varepsilon^{*} \in\left(\varepsilon_{\min }, \varepsilon_{\max }\right)$. A sufficient condition is

$$
0<\mu<\frac{\frac{1}{\beta}-1+\delta}{\max _{\varepsilon^{*} \in\left[\varepsilon_{\min }, \varepsilon_{\max }\right]} \frac{1-F\left(\varepsilon\left(\varepsilon^{*}\right)\right)}{F\left(\varepsilon^{*}\right)} \int_{\varepsilon_{\min }}^{\varepsilon_{\max }} \max \left(\varepsilon^{*}, \varepsilon\right) d F(\varepsilon) \frac{1-\frac{\lambda \beta}{\Pi} F\left(\varepsilon^{*}\right)}{1-\lambda}+\int_{\varepsilon\left(\varepsilon^{*}\right)}^{\varepsilon_{\max }}\left(\varepsilon-\varepsilon\left(\varepsilon^{*}\right)\right) d F(\varepsilon)} .
$$

Proof. Using (52), we can compute that

$$
\begin{aligned}
& \frac{d R_{k}\left(\varepsilon^{*}\right)}{d \varepsilon^{*}} \\
= & \frac{\mu\left[1-F\left(\varepsilon^{* *}\right)\right] \int_{\varepsilon_{\min }}^{\varepsilon_{\max }} \max \left(\varepsilon^{*}, \varepsilon\right) d F(\varepsilon) \frac{d \varepsilon^{* *}}{d \varepsilon^{*}}-\left[\frac{1}{\beta}-1+\delta-\mu \int_{\varepsilon^{* *}}^{\varepsilon_{\max }}\left(\varepsilon-\varepsilon^{* *}\right) d F(\varepsilon)\right] F\left(\varepsilon^{*}\right)}{\left[\int_{\varepsilon_{\min }}^{\varepsilon_{\max }} \max \left(\varepsilon^{*}, \varepsilon\right) d F(\varepsilon)\right]^{2}} \\
= & \frac{\mu\left(1-F\left(\varepsilon^{* *}\right)\right) \int_{\varepsilon_{\min }}^{\varepsilon_{\max }} \max \left(\varepsilon^{*}, \varepsilon\right) d F(\varepsilon) \frac{1-\frac{\lambda \beta}{\Pi} F\left(\varepsilon^{*}\right)}{1-\lambda}-\left[\frac{1}{\beta}-1+\delta-\mu \int_{\varepsilon^{* *}}^{\varepsilon_{\max }}\left(\varepsilon-\varepsilon^{* *}\right) d F(\varepsilon)\right] F\left(\varepsilon^{*}\right)}{\left[\int_{\varepsilon_{\min }}^{\varepsilon_{\max }} \max \left(\varepsilon^{*}, \varepsilon\right) d F(\varepsilon)\right]^{2}} .
\end{aligned}
$$

If $\mu=0$,

$$
\frac{d R_{k}\left(\varepsilon^{*}\right)}{d \varepsilon^{*}}=-\frac{\frac{1}{\beta}-1+\delta}{\left[\int_{\varepsilon_{\min }}^{\varepsilon_{\max }} \max \left(\varepsilon^{*}, \varepsilon\right) d F(\varepsilon)\right]^{2}}<0 .
$$

Since $R_{k}\left(\varepsilon^{*}\right)$ is a continuous function, the above inequality is also true for a sufficiently small $\mu$.

Define the function

$$
H\left(\varepsilon^{*}\right)=\left(R_{k}\left(\varepsilon^{*}\right)+\frac{\lambda \mu}{1-\lambda} \frac{1-F\left(\varepsilon\left(\varepsilon^{*}\right)\right)}{\Pi}\right) \int_{\varepsilon^{*}}^{\varepsilon_{\max }} \varepsilon d F(\varepsilon)+\mu \int_{\varepsilon\left(\varepsilon^{*}\right)}^{\varepsilon_{\max }} \varepsilon d F(\varepsilon),
$$


for $\varepsilon^{*} \in\left[\underline{\varepsilon}, \varepsilon_{\max }\right]$. Since $\varepsilon\left(\varepsilon^{*}\right)$ increases with $\varepsilon^{*}$, it follows from the preceding lemma that $H\left(\varepsilon^{*}\right)$ decreases with $\varepsilon^{*}$. Note that $H\left(\varepsilon_{\max }\right)=0$ and

$$
H(\underline{\varepsilon})=\left(R_{k}(\underline{\varepsilon})+\frac{\lambda \mu}{1-\lambda} \frac{1-F(\varepsilon(\underline{\varepsilon}))}{\Pi}\right) \int_{\underline{\varepsilon}}^{\varepsilon_{\max }} \varepsilon d F(\varepsilon)+\mu \int_{\varepsilon(\underline{\varepsilon})}^{\varepsilon_{\max }} \varepsilon d F(\varepsilon)>\delta,
$$

given the following assumption

$$
\mu>\frac{\delta-R_{k}(\underline{\varepsilon}) \int_{\underline{\varepsilon}}^{\varepsilon_{\max }} \varepsilon d F(\varepsilon)}{\frac{\lambda}{1-\lambda} \frac{1-F(\varepsilon(\underline{\varepsilon}))}{\Pi} \int_{\underline{\varepsilon}}^{\varepsilon_{\max }} \varepsilon d F(\varepsilon)+\int_{\varepsilon(\underline{\varepsilon})}^{\varepsilon_{\max }} \varepsilon d F(\varepsilon)} .
$$

By the intermediate value theorem, there exists a unique solution for $\varepsilon_{f}^{*} \in\left(\underline{\varepsilon}, \varepsilon_{\max }\right)$ to the equation $H\left(\varepsilon^{*}\right)=\delta$. Since $\varepsilon_{f}^{*}>\underline{\varepsilon}$, it follows Lemma 1 and (50) that $R_{f}=R\left(\varepsilon_{f}^{*}\right)>R(\underline{\varepsilon})=1$. Finally, the additional assumptions on $\mu$ not explicitly specified in the proposition are (A.18) and (A.20). Q.E.D.

Proof of Proposition 3: Equation (52) gives $R_{k f}=R_{k}\left(\varepsilon_{f}^{*}\right)$. Since $R_{k f}=\alpha Y_{f} / K_{f}$, we can determine $Y_{f} / K_{f}$. We now use the following procedure to derive other bubbleless steady-state variables. Equation (54) determines $m_{f} / K_{f}$. Equation (45) gives

$$
\frac{I_{f}}{K_{f}}=\left(R_{k f}+\frac{m_{f}}{\Pi K_{f}}\right)\left[1-F\left(\varepsilon_{f}^{*}\right)\right]+\mu\left[1-F\left(\varepsilon_{f}^{* *}\right)\right] .
$$

Thus we can derive $I_{f} / Y_{f}=\left(I_{f} / K_{f}\right) /\left(Y_{f} / K_{f}\right)$, and hence $C_{f} / Y_{f}=1-I_{f} / Y_{f}$.

Using (6), we can derive that

$$
\psi=\frac{w_{f}}{C_{f}}=(1-\alpha) \frac{Y_{f}}{N_{f}} \frac{1}{C_{f}}
$$

and thus

$$
N_{f}=\frac{1-\alpha}{\psi} \frac{Y_{f}}{C_{f}}
$$

Now we use $R_{k f}=\alpha A K_{f}^{\alpha-1} N_{f}^{1-\alpha}$ to solve for $K_{f}$ and then use the ratios derived above to determine $Y_{f}, m_{f}, I_{f}$, and $C_{f}$.

Consider the function $H$ defined in (A.19). It decreases with $\Pi$. Since the solution for $\varepsilon_{f}^{*}$ is given by the intersection of the downward sloping curve $H\left(\varepsilon^{*}\right)$ and the line $\delta$. Thus $\varepsilon_{f}^{*}$ decreases with П. Since $R_{k f}=\alpha K_{f}^{\alpha-1} N_{f}^{1-\alpha}=\alpha Y_{f} / K_{f}=R_{k}\left(\varepsilon_{f}^{*}\right)$, it follows from Lemma 2 that $K_{f} / N_{f}$ decreases with $\Pi$, but $Y_{f} / K_{f}$ increases with $\Pi$. The rest of results are straightforward to prove and hence are omitted. Q.E.D.

Proof of Proposition 4: We first prove sufficiency. Suppose that (56) holds. Define the function

$$
G\left(\varepsilon^{*}\right)=\beta s\left(1+(1-\omega) \int_{\varepsilon^{*}}^{\varepsilon_{\max }}\left(\frac{\varepsilon}{\varepsilon^{*}}-1\right) d F(\varepsilon)\right)+\beta s \theta \omega \int_{\varepsilon\left(\varepsilon^{*}\right)}^{\varepsilon_{\max }}\left(\frac{\varepsilon}{\varepsilon^{*}}-\frac{\varepsilon\left(\varepsilon^{*}\right)}{\varepsilon^{*}}\right) d F(\varepsilon)
$$

for $\varepsilon^{*} \in\left[\varepsilon_{f}^{*}, \varepsilon_{\max }\right)$. Since $R\left(\varepsilon^{*}\right)$ increases with $\varepsilon^{*}$, it follows from (51) that $\varepsilon\left(\varepsilon^{*}\right)$ and $\varepsilon\left(\varepsilon^{*}\right) / \varepsilon^{*}$ increase with $\varepsilon^{*}$. Thus $G\left(\varepsilon^{*}\right)$ decreases with $\varepsilon^{*}$. Moreover, $G\left(\varepsilon_{\max }\right)=\beta<1$ and $G\left(\varepsilon_{f}^{*}\right)<1$ by (56). By the intermediate value theorem, there exists a unique solution $\varepsilon_{b}^{*} \in\left(\varepsilon_{f}^{*}, \varepsilon_{\max }^{*}\right)$ to (55). 
Since $R_{f}=R\left(\varepsilon_{f}^{*}\right)>1$ and $R\left(\varepsilon^{*}\right)$ increases with $\varepsilon^{*}$, we have $R\left(\varepsilon_{b}^{*}\right)>R\left(\varepsilon_{f}^{*}\right)>1$. Once the bubbly steady-state cutoff $\varepsilon_{b}^{*}$ is determined, other bubbly steady-state values can be easily solved.

In particular, we use equation (51) to derive $\varepsilon_{b}^{* *}=\varepsilon\left(\varepsilon_{b}^{*}\right)$. Equation (52) gives $R_{k b}=R_{k}\left(\varepsilon_{b}^{*}\right)$. Since $R_{k b}=\alpha Y_{b} / K_{b}$, we can determine $Y_{b} / K_{b}$. The steady-state version of equation (46) implies that

$$
\frac{\delta}{\int_{\varepsilon_{b}^{*}}^{\varepsilon_{\max }} \varepsilon d F(\varepsilon)}=\left(R_{k}\left(\varepsilon_{b}^{*}\right)+\frac{m_{b}}{K_{b}} \frac{1}{\Pi}+(1-\omega) \frac{p^{h}}{K_{b}}\right)+\left(\theta \omega \frac{p^{h}}{K_{b}}+\mu\right) \frac{\int_{\varepsilon\left(\varepsilon_{b}^{*}\right)}^{\varepsilon_{\max }} \varepsilon d F(\varepsilon)}{\int_{\varepsilon_{b}^{*}}^{\varepsilon_{\max }} \varepsilon d F(\varepsilon)},
$$

where we use equation (43) to derive

$$
\frac{m_{b}}{K_{b}}=\frac{\lambda}{1-\lambda}\left(\theta \omega \frac{p^{h}}{K_{b}}+\mu\right)\left(1-F\left(\varepsilon_{b}^{* *}\right)\right) .
$$

Using these two equations, we can solve for $p^{h} / K_{b}$ and $m_{b} / K_{b}$,

$$
\frac{p_{h}}{K_{b}}=\frac{\delta-\left[R_{k}\left(\varepsilon_{b}^{*}\right)+\frac{\mu}{\Pi} \frac{\lambda}{1-\lambda}\left(1-F\left(\varepsilon\left(\varepsilon_{b}^{*}\right)\right)\right)\right] \int_{\varepsilon_{b}^{*}}^{\varepsilon_{\max }} \varepsilon d F(\varepsilon)-\mu \int_{\varepsilon\left(\varepsilon_{b}^{*}\right)}^{\varepsilon_{\max }} \varepsilon d F(\varepsilon)}{\frac{\theta \omega}{\Pi} \frac{\lambda}{1-\lambda}\left[1-F\left(\varepsilon\left(\varepsilon_{b}^{*}\right)\right)\right] \int_{\varepsilon_{b}^{*}}^{\varepsilon_{\max }^{*}} \varepsilon d F(\varepsilon)+(1-\omega) \int_{\varepsilon_{b}^{*}}^{\varepsilon_{\max }} \varepsilon d F(\varepsilon)+\theta \omega \int_{\varepsilon\left(\varepsilon_{b}^{*}\right)}^{\varepsilon_{\max }} \varepsilon d F(\varepsilon)} .
$$

We can show that the numerator on the right side of the equation above is an increasing function of $\varepsilon_{b}^{*}$ when $\mu$ is sufficiently small. Since that expression is equal to zero when $\varepsilon_{b}^{*}$ is replaced with $\varepsilon_{f}^{*}($ see $(53))$, it follows from $\varepsilon_{b}^{*}>\varepsilon_{f}^{*}$ that $p_{h} / K_{b}>0$.

Using (45), we can solve for $I_{b} / K_{b}$ and hence $I_{b} / Y_{b}=\left(I_{b} / K_{b}\right) /\left(Y_{b} / K_{b}\right)$. It follows from the resources constraint that $C_{b} / Y_{b}=1-I_{b} / Y_{b}$. Using (6) and $w_{b}=(1-\alpha) Y_{b} / N_{b}$, we can show that

$$
N_{b}=\frac{1-\alpha}{\psi} \frac{Y_{b}}{C_{b}}
$$

Using $R_{k b}=\alpha K_{b}^{\alpha-1} N_{b}^{1-\alpha}$, we can solve for $K_{b}$. We can then determine other equilibrium variables using the ratios derived above.

We next prove necessity. Suppose that a bubbly steady state exists. In a bubbly steady state $p^{h}>0$ and in a bubbleless steady state $p^{h}=0$. Since (A.23) holds for both bubbly and bubbleless steady states, we have

$$
\begin{aligned}
\delta & =\left[R_{k}\left(\varepsilon_{f}^{*}\right)+\frac{\lambda}{1-\lambda} \frac{\mu}{\Pi}\left(1-F\left(\varepsilon\left(\varepsilon_{f}^{*}\right)\right)\right)\right] \int_{\varepsilon_{f}^{*}}^{\varepsilon_{\max }} \varepsilon d F(\varepsilon)+\mu \int_{\varepsilon\left(\varepsilon_{f}^{*}\right)}^{\varepsilon_{\max }} \varepsilon d F(\varepsilon) \\
& >\left[R_{k}\left(\varepsilon_{b}^{*}\right)+\frac{\lambda}{1-\lambda} \frac{\mu}{\Pi}\left(1-F\left(\varepsilon\left(\varepsilon_{b}^{*}\right)\right)\right)\right] \int_{\varepsilon_{b}^{*}}^{\varepsilon_{\max }} \varepsilon d F(\varepsilon)+\mu \int_{\varepsilon\left(\varepsilon_{b}^{*}\right)}^{\varepsilon_{\max }} \varepsilon d F(\varepsilon) .
\end{aligned}
$$

When $\mu$ is sufficient small, Lemma 2 implies that $R_{k}\left(\varepsilon^{*}\right)$ decreases with $\varepsilon^{*}$. We have also shown that $\varepsilon\left(\varepsilon^{*}\right)$ increases with $\varepsilon^{*}$. Thus we deduce that

$$
\left[R_{k}\left(\varepsilon^{*}\right)+\frac{\lambda}{1-\lambda} \frac{\mu}{\Pi}\left(1-F\left(\varepsilon\left(\varepsilon^{*}\right)\right)\right)\right] \int_{\varepsilon^{*}}^{\varepsilon_{\max }} \varepsilon d F(\varepsilon)+\mu \int_{\varepsilon\left(\varepsilon^{*}\right)}^{\varepsilon_{\max }} \varepsilon d F(\varepsilon)
$$

decreases with $\varepsilon^{*}$. The preceding inequality then implies that $\varepsilon_{b}^{*}>\varepsilon_{f}^{*}$. We have shown that $G\left(\varepsilon^{*}\right)$ defined in (A.22) decreases with $\varepsilon^{*}$. Since in a bubbly steady state, equation (42) implies that $G\left(\varepsilon_{b}^{*}\right)=1$. It follows from $\varepsilon_{b}^{*}>\varepsilon_{f}^{*}$ that $G\left(\varepsilon_{f}^{*}\right)>1$. Q.E.D. 
Proof of Proposition 5: In the bubbly steady state, $G\left(\varepsilon_{b}^{*}\right)=1$ where $G$ is defined in (A.22). Since

$$
\frac{\varepsilon_{b}^{* *}}{\varepsilon_{b}^{*}}=\frac{\varepsilon\left(\varepsilon_{b}^{*}\right)}{\varepsilon_{b}^{*}}=\frac{R_{l b}}{R_{b}}>1
$$

we have

$$
\int_{\varepsilon\left(\varepsilon_{b}^{*}\right)}^{\varepsilon_{\max }}\left(\frac{\varepsilon}{\varepsilon_{b}^{*}}-\frac{\varepsilon\left(\varepsilon_{b}^{*}\right)}{\varepsilon_{b}^{*}}\right) d F(\varepsilon)<\int_{\varepsilon_{b}^{*}}^{\varepsilon_{\max }}\left(\frac{\varepsilon}{\varepsilon_{b}^{*}}-1\right) d F(\varepsilon) .
$$

Thus

$$
\begin{aligned}
& \beta s\left(1+(1-\omega) \int_{\varepsilon_{b}^{*}}^{\varepsilon_{\max }}\left(\frac{\varepsilon}{\varepsilon_{b}^{*}}-1\right) d F(\varepsilon)\right)+\beta s \theta \omega \int_{\varepsilon_{b}^{*}}^{\varepsilon_{\max }}\left(\frac{\varepsilon}{\varepsilon_{b}^{*}}-1\right) d F(\varepsilon) \\
>\quad & G\left(\varepsilon_{b}^{*}\right)=1 .
\end{aligned}
$$

This implies that

$$
\int_{\varepsilon_{b}^{*}}^{\varepsilon_{\max }}\left(\frac{\varepsilon}{\varepsilon_{b}^{*}}-1\right) d F(\varepsilon)>\frac{\frac{1}{\beta s}-1}{1-\omega+\theta \omega}
$$

By (50), we have

$$
1<R\left(\varepsilon_{b}^{*}\right)=\frac{\Pi}{\beta\left(1+\int_{\varepsilon_{b}^{*}}^{\varepsilon_{\max }}\left(\frac{\varepsilon}{\varepsilon_{b}^{*}}-1\right) d F(\varepsilon)\right)}<\frac{1}{\beta} \frac{\Pi}{1+\frac{1 /(\beta s)-1}{1-\omega+\theta \omega}} .
$$

Thus

$$
\Pi>\beta+\frac{1 / s-\beta}{1-\omega+\theta \omega}>1
$$

Moreover, since $\varepsilon_{b}^{*}>\varepsilon_{f}^{*}$,

$$
\Pi>\frac{1}{\beta} \frac{\Pi}{1+\frac{1 /(\beta s)-1}{1-\omega+\theta \omega}}>R\left(\varepsilon_{b}^{*}\right)>R\left(\varepsilon_{f}^{*}\right) .
$$

We then obtain the desired result. Q.E.D.

Proof of Proposition 6: In the proof of Proposition 5 we have show that $\varepsilon_{f}^{*}$ decreases with $\Pi$. Since the left side of (56) is a decrease function $\varepsilon_{f}^{*}$, condition (56) is more likely to hold for a higher I. Q.E.D.

\section{B Log-linearized System}

The log-linearized equilibrium system can be described by 17 equations for 17 variables $\left\{\hat{C}_{t}, \hat{I}_{t}, \hat{K}_{t}\right.$, $\left.\hat{Y}_{t}, \hat{N}_{t}, \hat{\Pi}_{t}, \hat{p}_{w t}, \hat{w}_{t}, \hat{p}_{h t}, \hat{q}_{t}^{k}, \hat{R}_{k t}, \hat{\varepsilon}_{t}^{*}, \hat{\varepsilon}_{t}^{* *}, \hat{R}_{l t}, \hat{m}_{t}, \hat{g}_{t}, \hat{R}_{t}\right\}$.

- Aggregate demand

$$
\begin{aligned}
& \hat{C}_{t}=E_{t} \hat{C}_{t+1}-\left(\hat{R}_{t}-E_{t} \hat{\Pi}_{t+1}\right)+\frac{R \beta}{\Pi} \int_{\varepsilon^{*}}^{\varepsilon_{\max }} \frac{\varepsilon}{\varepsilon^{*}} d F(\varepsilon) E_{t} \hat{\varepsilon}_{t+1}^{*}, \\
\hat{I}_{t}= & \frac{R_{k} K}{I}\left(1-F\left(\varepsilon^{*}\right)\right)\left(\hat{R}_{k t}+\hat{K}_{t}\right)+\frac{m}{\Pi}\left(1-F\left(\varepsilon^{*}\right)\right)\left(\hat{m}_{t}-\hat{\Pi}_{t}\right) \\
+ & \left(1-F\left(\varepsilon^{* *}\right)\right) \frac{\mu K}{I} \hat{K}_{t}+\left[\left(1-F\left(\varepsilon^{*}\right)\right)(1-\omega)+\left(1-F\left(\varepsilon^{* *}\right)\right) \theta \omega\right] \frac{p_{h}}{I} \hat{p}_{h t} \\
& -\left[R_{k} K+\frac{m}{\Pi}+(1-\omega) p_{h}\right] \frac{f\left(\varepsilon^{*}\right) \varepsilon^{*}}{I} \hat{\varepsilon}_{t}^{*}-\left(\theta \omega p_{h}+\mu K\right) \frac{f\left(\varepsilon^{* *}\right) \varepsilon^{* *}}{I} \hat{\varepsilon}_{t}^{* *},
\end{aligned}
$$




$$
\begin{aligned}
& \hat{K}_{t+1}=(1-\delta) \hat{K}_{t}+R_{k} \int_{\varepsilon^{*}}^{\varepsilon_{\max }} \varepsilon d F(\varepsilon)\left(\hat{K}_{t}+\hat{R}_{k t}\right) \\
&+\mu \int_{\varepsilon^{* *}}^{\varepsilon_{\max }} \varepsilon d F(\varepsilon) \hat{K}_{t}+\frac{m}{\Pi K} \int_{\varepsilon^{*}}^{\varepsilon_{\max }} \varepsilon d F(\varepsilon)\left(\hat{m}_{t}-\hat{\Pi}_{t}\right) \\
&+\left[(1-\omega) \int_{\varepsilon^{*}}^{\varepsilon_{\max }} \varepsilon d F(\varepsilon)+\theta \omega \int_{\varepsilon^{* *}}^{\varepsilon_{\max }} \varepsilon d F(\varepsilon)\right] \frac{p^{h}}{K} \hat{p}_{t}^{h} \\
&-\left[R_{k}+\frac{m}{\Pi K}+(1-\omega) \frac{p^{h}}{K}\right]\left(\varepsilon^{*}\right)^{2} f\left(\varepsilon^{*}\right) \hat{\varepsilon}_{t}^{*}-\left(\theta \omega \frac{p^{h}}{K}+\mu\right)\left(\varepsilon^{* *}\right)^{2} f\left(\varepsilon^{* *}\right) \hat{\varepsilon}_{t}^{* *}, \\
& \hat{Y}_{t}=\frac{C}{Y} \hat{C}_{t}+\frac{I}{Y} \hat{I}_{t} .
\end{aligned}
$$

- Aggregate supply

$$
\begin{gathered}
\hat{\Pi}_{t}=\frac{1}{\xi}(1-\xi)(1-\beta \xi) \hat{p}_{w t}+\beta E_{t} \hat{\Pi}_{t+1}, \\
\hat{Y}_{t}=\hat{A}_{t}+\alpha \hat{K}_{t}+(1-\alpha) \hat{N}_{t} \\
\hat{w}_{t}=\hat{p}_{w t}+\hat{A}_{t}+\alpha \hat{K}_{t}-\alpha \hat{N}_{t} \\
\hat{C}_{t}=\hat{w}_{t} .
\end{gathered}
$$

- Asset prices

$$
\begin{gathered}
\hat{p}_{t}^{h}=E_{t} \hat{p}_{t+1}^{h}+\hat{C}_{t}-E_{t} \hat{C}_{t+1}+\hat{s}_{t}-s \beta \theta \omega\left[1-F\left(\varepsilon^{* *}\right)\right] \frac{\varepsilon^{* *}}{\varepsilon^{*}} E_{t} \hat{\varepsilon}_{t+1}^{* *} \\
-s \beta\left[(1-\omega) \int_{\varepsilon^{*}}^{\varepsilon_{\max }} \frac{\varepsilon}{\varepsilon^{*}} d F(\varepsilon)+\theta \omega \frac{1}{\varepsilon^{*}} \int_{\varepsilon^{* *}}^{\varepsilon_{\max }}\left(\varepsilon-\varepsilon^{* *}\right) d F(\varepsilon)\right] E_{t} \hat{\varepsilon}_{t+1}^{*}, \\
\hat{q}_{t}^{k}=\hat{C}_{t}-E_{t} \hat{C}_{t+1}+\frac{R_{k} \Pi}{q^{k} R} E_{t} \hat{R}_{k t+1}+\beta(1-\delta) E_{t} \hat{q}_{t+1}^{k}-\beta \mu \varepsilon^{* *}\left[1-F\left(\varepsilon^{* *}\right)\right] E_{t} \hat{\varepsilon}_{t+1}^{* *} \\
-\beta\left[\mu \int_{\varepsilon^{* *}}^{\varepsilon_{\max }}\left(\varepsilon-\varepsilon^{* *}\right) d F(\varepsilon)+R_{k} \int_{\varepsilon^{*}}^{\varepsilon_{\max }} \varepsilon d F(\varepsilon)\right] E_{t} \hat{\varepsilon}_{t+1}^{*}, \\
\hat{R}_{k t}=\hat{p}_{w t}+\hat{A}_{t}+(\alpha-1) \hat{K}_{t}+(1-\alpha) \hat{N}_{t} .
\end{gathered}
$$

- Lending rate and two cutoffs

$$
\begin{gathered}
\hat{R}_{l t}-\hat{R}_{t}=\hat{\varepsilon}_{t}^{* *}-\hat{\varepsilon}_{t}^{*}, \\
\hat{\varepsilon}_{t}^{*}=-\hat{q}_{t}^{k}, \\
\hat{\varepsilon}_{t}^{* *}=\hat{\varepsilon}_{t}^{*}+\frac{\lambda / R}{1-\lambda / R} \hat{R}_{t} .
\end{gathered}
$$

- Money demand and supply

$$
\begin{gathered}
\hat{m}_{t+1}=\frac{\theta \omega p_{h}}{\theta \omega p_{h}+\mu K} \hat{p}_{h t}+\frac{\mu K}{\theta \omega p_{h}+\mu K} \hat{k}_{t}-\frac{\varepsilon^{* *} f\left(\varepsilon^{* *}\right)}{1-F\left(\varepsilon^{* *}\right)} \hat{\varepsilon}_{t}^{* *}, \\
\hat{m}_{t+1}=\hat{m}_{t}-\hat{\Pi}_{t}+\hat{g}_{t} .
\end{gathered}
$$


- Interest rate rule

$$
\hat{R}_{t}=\phi_{\pi} \hat{\Pi}_{t}+\phi_{y} \hat{Y}_{t}+\phi_{p} \hat{p}_{h t}+\hat{v}_{t},
$$

or

$$
\hat{R}_{t}=\phi_{\pi} E_{t} \hat{\Pi}_{t+1}+\phi_{p} \hat{p}_{h t}+\hat{v}_{t},
$$

- Exogenous shocks

$$
\begin{aligned}
\hat{A}_{t} & =\rho_{a} \hat{A}_{t-1}+\varepsilon_{a t}, \\
\hat{v}_{t} & =\rho_{v} \hat{v}_{t-1}+\varepsilon_{v t}, \\
\hat{s}_{t} & =\rho_{s} \hat{s}_{t-1}+\varepsilon_{s t} .
\end{aligned}
$$

